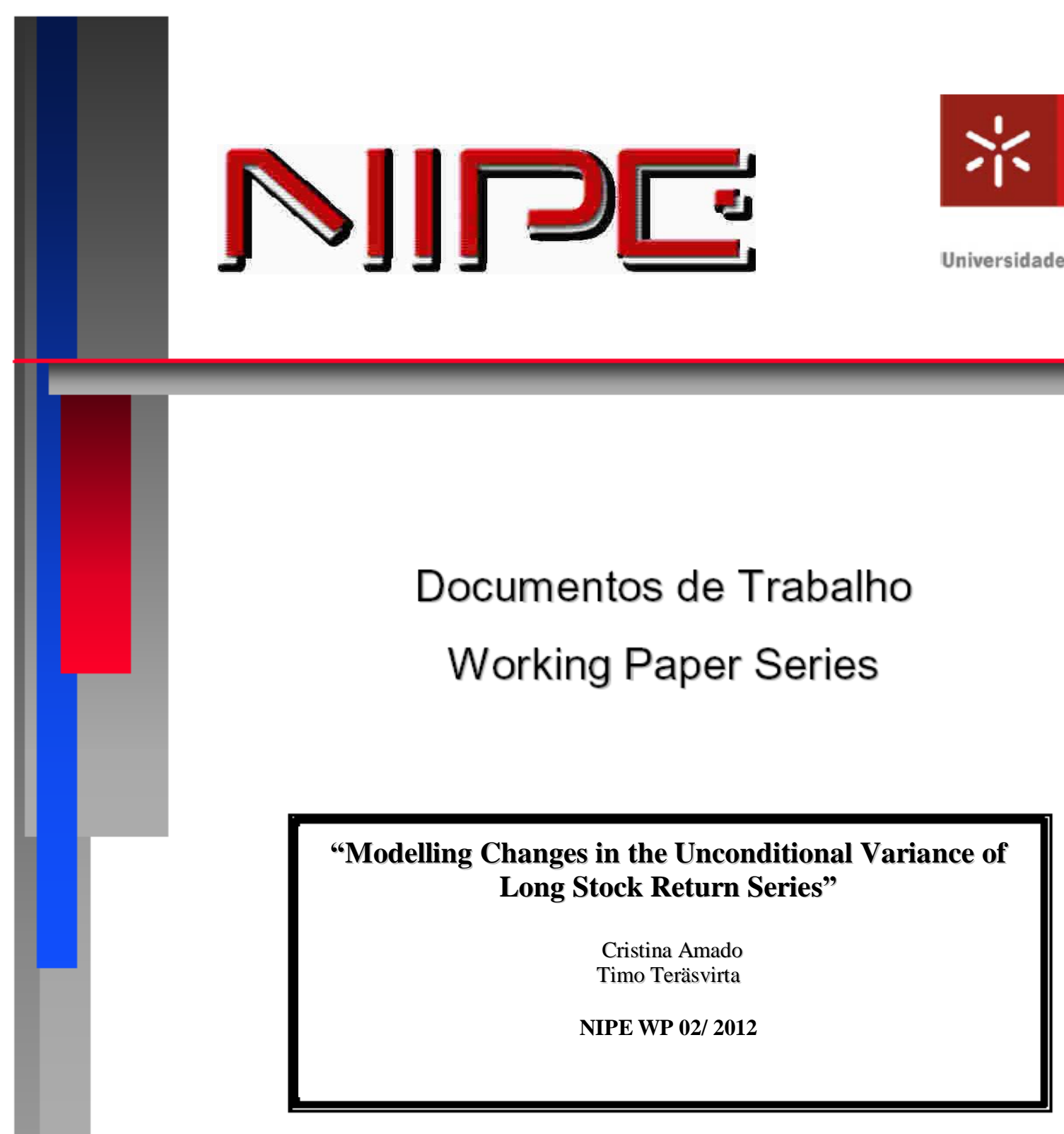

NÚCLEO DE INVESTIGAÇÃO EM POLÍTICAS ECONÓMICAS UNIVERSIDADE DO MINHO 


\section{"Modelling Changes in the Unconditional Variance of Long Stock Return Series"}

Cristina Amado

Timo Teräsvirta

NIPE* WP 02/ 2012

URL:

http://www.eeg.uminho.pt/economia/nipe
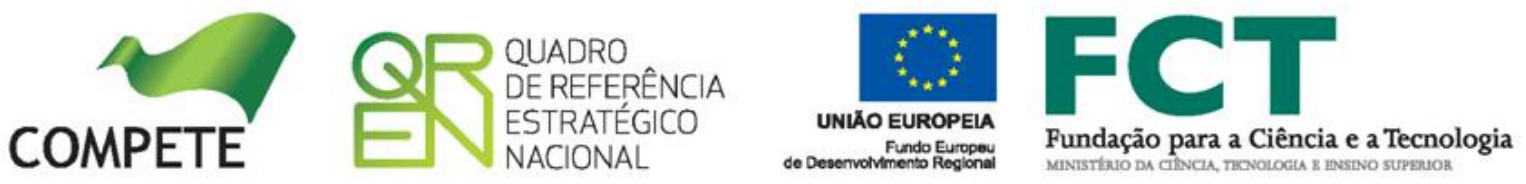


\title{
Modelling Changes in the Unconditional Variance of Long Stock Return Series
}

\author{
Cristina Amado* \\ University of Minho and NIPE \\ Campus de Gualtar, 4710-057 Braga, Portugal \\ Timo Teräsvirta ${ }^{\dagger}$ \\ CREATES, Department of Economics and Business, Aarhus University \\ Building 1322, DK-8000 Aarhus, Denmark
}

February 2012

\footnotetext{
${ }^{*}$ E-mail: camado@eeg.uminho.pt

${ }^{\dagger}$ E-mail: tterasvirta@econ.au.dk

Acknowledgements: This research has been supported by the Danish National Research Foundation. The first author would like to acknowledge financial support from the Louis Fraenckels Stipendiefond. Part of this research was done while the first author was visiting CREATES, Aarhus University, whose kind hospitality is gratefully acknowledged. Material from this paper has been presented at the Workshop on Risk \& Extreme Values in Insurance and Finance, Lisbon, June 2011 and at the Macro and Financial Econometrics Conference, Heidelberg, September 2011. The responsibility for any errors and shortcomings in this paper remains ours.
} 


\begin{abstract}
In this paper we develop a testing and modelling procedure for describing the long-term volatility movements over very long return series. For the purpose, we assume that volatility is multiplicatively decomposed into a conditional and an unconditional component as in Amado and Teräsvirta (2011). The latter component is modelled by incorporating smooth changes so that the unconditional variance is allowed to evolve slowly over time. Statistical inference is used for specifying the parameterization of the time-varying component by applying a sequence of Lagrange multiplier tests. The model building procedure is illustrated with an application to daily returns of the Dow Jones Industrial Average stock index covering a period of more than ninety years. The main conclusions are as follows. First, the LM tests strongly reject the assumption of constancy of the unconditional variance. Second, the results show that the long-memory property in volatility may be explained by ignored changes in the unconditional variance of the long series. Finally, based on a formal statistical test we find evidence of the superiority of volatility forecast accuracy of the new model over the GJR-GARCH model at all horizons for a subset of the long return series.
\end{abstract}

JEL classification: C12; C22; C51; C52; C53

Key words: Model specification; Conditional heteroskedasticity; Lagrange multiplier test; Timevarying unconditional variance; Long financial time series; Volatility persistence. 


\section{Introduction}

The observation that deterministic shifts in long return series can generate long-memory behaviour has received much attention in recent years. Most of the work in this topic is related with the study of the behaviour of standard statistical tools and model misspecification under nonstationarity. Early studies include Diebold (1986) and Lamoureux and Lastrapes (1990) who suggested that occasional level shifts in the intercept of the first-order GARCH model can bias the estimation towards an integrated GARCH model. More recently, Mikosch and Stărică (2004) argued that the so-called 'integrated GARCH effect' is caused by the nonstationary behaviour of very long return series. They showed how the long-range dependence in volatility and the IGARCH effect may be explained by neglected deterministic changes in the unconditional variance of the stochastic process. Moreover, Granger and Hyung (2004) claimed that occasional breaks in a long time series of absolute stock returns can also explain the observed slow decay of the autocorrelation functions of absolute returns in long return series.

In a standard first-order GARCH model of Bollerslev (1986) the decay rate of the autocorrelation function of squared observations is exponential, which is often considered too rapid. This has motivated the development of more flexible models to describe the observed dependence structure in financial market volatility. One of these models is the Fractionally Integrated GARCH model of Baillie, Bollerslev, and Mikkelsen (1996) which belongs to the class of longmemory models. In these processes, the decay rate of the autocorrelations of squares is hyperbolic, which often appears more suitable for financial series than the exponential rate of the GARCH model. Baillie and Morana (2009) recently proposed a generalization of the FIGARCH model in which the intercept changes deterministically according to the flexible functional form of Gallant (1984).

The question of explicitly modelling nonstationarity in stock market volatility has received somewhat less attention. van Bellegem and von Sachs (2004) proposed decomposing the volatility process multiplicatively into a deterministic nonstationary (or the unconditional variance) and a stochastic stationary (or the conditional variance) component. The deterministic component in their model is estimated nonparametrically. Stărică and Granger (2005) introduced a nonstationary approach in which the returns are modelled as nonstationary sequence of independent random variables with time-varying unconditional variance but their model does not allow for volatility clustering. More recently, Engle and Gonzalo Rangel (2008) and Brownlees and Gallo (2010) applied the same multiplicative decomposition as van Bellegem and von Sachs (2004). The deterministic nonstationary component is in their approach described by an exponential spline, and the stationary component follows a first-order GARCH process.

This paper addresses the issue of modelling deterministic changes in the unconditional variance of long return series. It is assumed that volatility is modelled by multiplicatively decomposing the variance into a conditional and an unconditional component as in Amado and Teräsvirta (2011). The conditional variance follows a GARCH process and describes the short-run dynamics of volatility. The nonstationary component of volatility describes the long-volatility dynamics, and it is represented by a linear combination of logistic transition functions. Statistical inference is used for specifying the parametric structure of the time-varying component by applying a sequence of Lagrange multiplier tests.

Our modelling strategy is applied to describe the long-run properties of the long daily Dow Jones Industrial Average (DJIA) return series from 1920 to 2011. One may expect that the longer the observation period, the more likely the occurrence of structural changes or shifts in the second unconditional moment of returns. The test results strongly support the time-variation of the unconditional variance in the period under study. The estimation results indicate that the strongest deterministic changes in the unconditional variance are associated with the largest economic recessions. This in turn suggests that the unconditional variance behaviour may be 
related to the evolution of the deterministic conditions in the economy. Our findings also suggest that the observed long-memory property in volatility may well be due to deterministic changes in the unconditional variance of the return series. Moreover, the out-of-sample forecasting accuracy of the proposed model is also studied over several forecasting horizons. Modelling the long-term volatility movements over a long return series generates more accurate volatility forecasts than the GJR-GARCH model for short-term horizons. However, the predictive ability of the new model is strikingly improved across all horizons by dropping the old observations and merely using the most recent observations.

The paper is organized as follows. The TV-GARCH model and the modelling strategy are presented in Section 2. Details regarding the estimation of the model are discussed in Section 3. Section 4 contains the application and Section 5 concludes.

\section{A model for the long-term volatility component}

\subsection{The time-varying GARCH framework}

In this paper the tool for modelling an asset return series over a long period is a GARCH-type model in which the unconditional variance is assumed to evolve smoothly over time. We begin by focusing on the long-run properties of the GJR-GARCH $(p, q)$ model of Glosten, Jagannathan, and Runkle (1993). Let $\mathcal{F}_{t-1}$ be the information set containing the historical information of the series of interest available at time $t-1$ and write the asset returns $\left\{y_{t}\right\}$ as

$$
\begin{aligned}
y_{t} & =\mathrm{E}\left(y_{t} \mid \mathcal{F}_{t-1}\right)+\varepsilon_{t} \\
\varepsilon_{t} & =\zeta_{t} h_{t}^{1 / 2}
\end{aligned}
$$

where $\left\{\zeta_{t}\right\} \sim \operatorname{nid}(0,1)$. Under this assumption the conditional distribution of the innovation sequence $\left\{\varepsilon_{t}\right\}$ is $\varepsilon_{t} \mid \mathcal{F}_{t-1} \sim N\left(0, h_{t}\right)$. For simplicity, the conditional mean of the asset returns is set equal to zero, i.e. $\mathrm{E}\left(\mathbf{y}_{t} \mid \mathcal{F}_{t-1}\right)=0$. The component $h_{t}$ describes the dynamics of the conditional variance of the asset returns. To allow positive and negative shocks to have an asymmetric effect on the stock market volatility we choose the GJR-GARCH $(p, q)$ model for $h_{t}$. It has the form

$$
h_{t}=\omega+\sum_{i=1}^{q} \alpha_{i} \varepsilon_{t-i}^{2}+\sum_{i=1}^{q} \kappa_{i} \varepsilon_{t-i}^{2} I_{t-i}\left(\varepsilon_{t-i}<0\right)+\sum_{j=1}^{p} \beta_{j} h_{t-j} .
$$

where the set of conditions for positivity and stationarity are imposed and where $I(A)$ is the indicator variable: $I(A)=1$ when $A$ is true, and zero otherwise. Re-writing the dynamic structure of (3) in terms of the unconditional variance $\sigma^{2}$ one obtains

$$
h_{t}=\sigma^{2}+\sum_{i=1}^{q} \alpha_{i}\left(\varepsilon_{t-i}^{2}-\sigma^{2}\right)+\sum_{i=1}^{q} \kappa_{i}\left(\varepsilon_{t-i}^{2} I_{t-i}\left(\varepsilon_{t-i}<0\right)-\sigma^{2}\right)+\sum_{j=1}^{p} \beta_{j}\left(h_{t-j}-\sigma^{2}\right)
$$

where $\sigma^{2} \equiv \mathrm{E}\left(\varepsilon_{t}^{2}\right)=\omega /\left(1-\sum_{i=1}^{q} \alpha_{i}-\sum_{i=1}^{q} \kappa_{i} / 2-\sum_{j=1}^{p} \beta_{j}\right)$. When the persistence rate $\sum_{i=1}^{q} \alpha_{i}+$ $\sum_{i=1}^{q} \kappa_{i} / 2+\sum_{j=1}^{p} \beta_{j}<1$, then the conditional variance mean reverts to $\sigma^{2}$ at the geometric rate $\sum_{i=1}^{q} \alpha_{i}+\sum_{i=1}^{q} \kappa_{i} / 2+\sum_{j=1}^{p} \beta_{j}$.

The assumption that the volatility process reverts to a constant level is very restrictive especially when modelling asset returns over long periods. In order to account for changes in the long-run volatility we shall consider a more flexible specification in which the unconditional variance $\sigma^{2}$ can be time-varying. We incorporate smooth changes in the unconditional variance 
of returns so that the variance evolves slowly over time. The variance is thus modelled using a multiplicative decomposition of the variance as follows:

$$
\varepsilon_{t}=\zeta_{t} h_{t}^{1 / 2} g_{t}^{1 / 2}, \quad \quad \varepsilon_{t} \mid \mathcal{F}_{t-1} \sim N\left(0, h_{t} g_{t}\right)
$$

where $g_{t}$ is a bounded deterministic positive-valued function. In equation (5) the short-run (or the stationary) component $h_{t}$ is modelled as the GJR-GARCH process as in (3), with the exception that $\varepsilon_{t}^{*}=\varepsilon_{t} / g_{t}^{1 / 2}$ :

$$
h_{t}=\omega+\sum_{i=1}^{q} \alpha_{i} \varepsilon_{t-i}^{* 2}+\sum_{i=1}^{q} \kappa_{i} \varepsilon_{t-i}^{* 2} I_{t-i}\left(\varepsilon_{t-i}^{*}<0\right)+\sum_{j=1}^{p} \beta_{j} h_{t-j} .
$$

The long-run (or the nonstationary) component $g_{t}$ is a slowly time-varying trend that functions as a proxy for all factors that affect the unconditional variance. We follow Amado and Teräsvirta (2011) and let the time-varying unconditional variance component be a linear combination of bounded transition functions:

$$
g_{t}=\delta_{0}+\sum_{l=1}^{r} \delta_{l} G_{l}\left(t / T ; \gamma_{l}, \mathbf{c}_{l}\right)
$$

where $\delta_{l}, l=0, \ldots, r$, are parameters. More specifically, $G_{l}\left(t / T ; \gamma_{l}, \mathbf{c}_{l}\right), l=1, \ldots, r$, are generalized logistic transition functions:

$$
G_{l}\left(t / T ; \gamma_{l}, \mathbf{c}_{l}\right)=\left(1+\exp \left\{-\gamma_{l} \prod_{j=1}^{k}\left(t / T-c_{l j}\right)\right\}\right)^{-1}
$$

satisfying the identification restrictions $\gamma_{l}>0, l=0, \ldots, r$, and $c_{l 1} \leq c_{l 2} \leq \ldots \leq c_{l k}$. The transition functions allow the unconditional variance to change smoothly as a function of the calendar time $t / T$. The parameters, $c_{l j}$ and $\gamma_{l}$, determine the location and the speed of the transition between different regimes. Equations (5)-(8) define the time-varying GJR-GARCH (TV-GJR-GARCH) model. The unconditional variance in this model is time-varying and equals $\mathrm{E}_{t}\left(\varepsilon_{t}^{2}\right)=\mathrm{E}\left(\zeta_{t}^{2} h_{t} g_{t}\right)=g_{t} \mathrm{E} h_{t}$. This way of introducing nonstationarity in the long run volatility component is discussed in detail by Amado and Teräsvirta (2011).

Some special cases of the TV-GJR-GARCH model are of interest. Under $\delta_{1}=\ldots=\delta_{r}=0$, the unconditional variance $\mathrm{E}_{t}\left(\varepsilon_{t}^{2}\right)$ becomes constant. When $r=1$ and $k=1, g_{t}$ increases (decreases) monotonically over time from $\delta_{0}$ to $\delta_{0}+\delta_{1}$ when $\delta_{1}>0\left(\delta_{1}<0\right)$, with the location centred at $t=c_{1} T$. The slope parameter $\gamma_{1}$ in (8) controls the degree of smoothness of the transition: the larger $\gamma_{1}$, the faster the transition is between the extreme regimes. When $\gamma_{1} \rightarrow$ $\infty, g_{t}$ collapses into a step function. When $\delta_{l} \neq 0$, for values $r>1$ and $k>1$, equations (7) and (8) form a very flexible parameterization capable of describing nonmonotonic deterministic changes in the unconditional variance.

\subsection{Model specification}

Since the nonlinear model in (5)-(8) is our most general parameterization, a systematic modelling strategy is required when a TV-GARCH type model is fitted to the data. The strategy for building TV-GARCH models is based on statistical inference and it consists of the specification, estimation and evaluation of the model. At the specification stage, one first models the dynamics of the short-run component $h_{t}$ and, once that has been done, specifies the structure of $g_{t}$. In practice, the parametric structure of the unconditional variance component has to be determined from the data, which involves two sets of decision problems. First, the number of 
transitions $r$ in (7) has to be determined. Second, when $r \geq 1$, the integer $k$ for each transition function has to be selected. This specification procedure is sequential and based on statistical inference. We shall apply the procedure of Amado and Teräsvirta (2011) for selecting $r$ and $k$.

An important feature of the modelling strategy in this paper is that, since we are modelling very long return series, we shall divide the observation period into a number of subperiods. To introduce notation, let $r$ be the total number of transitions in the whole period and $r_{i}, i=$ $1, \ldots, N$, be the number of transitions in the subperiod $i$, so $r=\sum_{i=1}^{N} r_{i}$. Define $h_{i t}$ as the conditional variance and $g_{i t}=1+\sum_{l=1}^{r_{i}} \delta_{i l} G_{i l}\left(t / T ; \gamma_{l}, \mathbf{c}_{l}\right), i=1, \ldots, N$, for each subperiod.

The sequence of LM tests for specifying a TV-GARCH model is as follows:

1. Divide the original time series into $N$ non-overlapping subsamples. To facilitate specification the borders of the subsamples should be located in tranquil periods.

2. For each $i=1, \ldots, N$, model the conditional variance $h_{i t}$ under the assumption that $g_{i t} \equiv 1$. The deterministic functions $g_{i t}$ are determined thereafter by sequential testing. This is done as follows. First, test the hypothesis of constant unconditional variance $\mathrm{H}_{01}: \gamma_{i 1}=0$ against $\mathrm{H}_{11}: \gamma_{i 1}>0$ in

$$
g_{i t}=1+\delta_{i 1} G_{i 1}\left(t / T ; \gamma_{i 1}, \mathbf{c}_{i 1}\right)
$$

at the significance level $\alpha^{(1)}$. The standard test statistic has a non-standard asymptotic distribution because $\delta_{i 1}$ and $\mathbf{c}_{i 1}$. are unidentified nuisance parameters when $\mathrm{H}_{01}$ is true. To circumvent this identification problem we follow Luukkonen, Saikkonen, and Teräsvirta (1988) and approximate $G_{i 1}\left(t / T ; \gamma_{i 1}, \mathbf{c}_{i 1}\right)$ by its third-order Taylor expansion around $\gamma_{i 1}=$ 0 . After reparameterizing, we obtain

$$
g_{i t}=\omega_{i}^{*}+\sum_{j=1}^{3} \phi_{i j}(t / T)^{j}+R_{3}\left(t / T ; \gamma_{i 1}, \mathbf{c}_{i 1}\right)
$$

where $\phi_{i j}=\gamma_{i 1}^{j} \widetilde{\delta}_{i j}^{*}, \widetilde{\delta}_{i j}^{*} \neq 0$, and $R_{3}\left(t / T ; \gamma_{i 1}, \mathbf{c}_{i 1}\right)$ is the remainder. Furthermore, $R_{3}\left(t / T ; \gamma_{i 1}, \mathbf{c}_{i 1}\right) \equiv$ 0 under $\mathrm{H}_{01}$, so the remainder of the Taylor expansion does not affect the asymptotic distribution theory. The new null hypothesis based on this approximation becomes $\mathrm{H}_{01}^{\prime}: \phi_{i 1}=$ $\phi_{i 2}=\phi_{i 3}=0$. Under $\mathrm{H}_{01}^{\prime}$, the standard LM statistic has an asymptotic $\chi^{2}$-distribution with three degrees of freedom. See Amado and Teräsvirta (2011) for details on how to compute the test statistic.

3. If $\mathrm{H}_{01}^{\prime}$ is rejected, for each subperiod select the order $k \leq 3$ in the exponent of $G_{i 1}\left(t / T ; \gamma_{i 1}, \mathbf{c}_{i 1}\right)$ using a short sequence of tests within (10); for details see Amado and Teräsvirta (2011). Next, estimate $g_{i t}$ with a single transition function and test $\mathrm{H}_{02}: \gamma_{i 2}=0$ against $\mathrm{H}_{12}$ : $\gamma_{i 2}>0$ in

$$
g_{i t}=1+\delta_{i 1} G_{i 1}\left(t / T ; \gamma_{i 1}, \mathbf{c}_{i 1}\right)+\delta_{i 2} G_{i 2}\left(t / T ; \gamma_{i 2}, \mathbf{c}_{i 2}\right)
$$

at the significance level $\alpha^{(2)}=\tau \alpha^{(1)}$, where $\tau \in(0,1)$. In our application we set $\tau=0.5$. The significance level is reduced at each stage by a factor $\tau$ in order to favour parsimony. Again, model (11) is not identified under the null hypothesis. To circumvent the problem we proceed as before and express the logistic function $G_{i 2}\left(t / T ; \gamma_{i 2}, \mathbf{c}_{i 2}\right)$ by a third-order Taylor approximation around $\gamma_{i 2}=0$. After rearranging terms we have

$$
g_{i t}=\omega_{i}^{*}+\delta_{i 1} G_{i 1}\left(t / T ; \gamma_{i 1}, \mathbf{c}_{i 1}\right)+\sum_{j=1}^{3} \varphi_{i j}(t / T)^{j}+R_{3}\left(t / T ; \gamma_{i 2}, \mathbf{c}_{i 2}\right)
$$

where $\varphi_{i j}=\gamma_{i 2}^{j} \widetilde{\delta}_{i j}^{*}, \widetilde{\delta}_{i j}^{*} \neq 0$ and $R_{3}\left(t / T ; \gamma_{i 2}, \mathbf{c}_{i 2}\right)$ is the remainder. The new null hypothesis based on this approximation becomes $\mathrm{H}_{02}^{\prime}: \varphi_{i 2}=\varphi_{i 2}=\varphi_{i 3}=0$. Again, this hypothesis 
can be tested using a LM test. If the null hypothesis is rejected, specify $k$ for the second transition and estimate $g_{i t}$ with two transition functions.

4. More generally, when $g_{i t}$ has been estimated with $r_{i}-1$ transition functions one tests for another transition in $g_{i t}$ using the significance level $\alpha^{\left(r_{i}\right)}=\tau \alpha^{\left(r_{i}-1\right)}, j=2,3, \ldots$ Testing continues until the first non-rejection of the null hypothesis.

In summary, we begin the model specification problem by first modelling the conditional variance component $h_{t}$ as in (6) with $p=q=1$. This may be preceded by testing the null hypothesis of no ARCH. Thereafter, if the unconditional variance is time-varying, one has to specify the unconditional variance component $g_{t}$. At the evaluation stage the adequacy of the estimated model is tested by means of LM-type misspecification tests, see Amado and Teräsvirta (2011) for details.

\section{Estimation of parameters}

After the number of transitions and their type in (7) have been determined, the parameters of the TV-GARCH model are estimated by quasi-maximum likelihood (QML). For this purpose, let $\boldsymbol{\theta}=\left(\boldsymbol{\theta}_{1}^{\prime}, \boldsymbol{\theta}_{2}^{\prime}\right)^{\prime}$ be the parameter vector of the model. Let $h_{t} \equiv h_{t}\left(\boldsymbol{\theta}_{1}, \boldsymbol{\theta}_{2}\right)$ and $g_{t} \equiv g_{t}\left(\boldsymbol{\theta}_{2}\right)$ where $\boldsymbol{\theta}_{1}=\left(\omega, \boldsymbol{\alpha}^{\prime}, \boldsymbol{\kappa}^{\prime}, \boldsymbol{\beta}^{\prime}\right)$ and $\boldsymbol{\theta}_{2}=\left(\delta_{0}, \boldsymbol{\delta}^{\prime}, \gamma_{1}, \ldots, \gamma_{r}, \mathbf{c}_{1}^{\prime}, \ldots, \mathbf{c}_{r}^{\prime}\right)^{\prime}$ with $\boldsymbol{\alpha}=\left(\alpha_{1}, \ldots, \alpha_{q}\right)^{\prime}, \boldsymbol{\kappa}=$ $\left(\kappa_{1}, \ldots, \kappa_{q}\right)^{\prime}, \boldsymbol{\beta}=\left(\beta_{1}, \ldots, \beta_{p}\right)^{\prime}, \boldsymbol{\delta}=\left(\delta_{1}, \ldots, \delta_{r}\right)^{\prime}$. The model defined in (5)-(8) can be now rewritten as follows:

$$
\varepsilon_{t}=\zeta_{t}\left\{h_{t}\left(\boldsymbol{\theta}_{1}, \boldsymbol{\theta}_{2}\right) g_{t}\left(\boldsymbol{\theta}_{2}\right)\right\}^{1 / 2} .
$$

Assuming that $\left\{\zeta_{t}\right\}$ is a sequence of independent standard normal variables, the log-likelihood function for observation $t$ equals

$$
\ell_{t}(\boldsymbol{\theta})=-(1 / 2) \ln 2 \pi-(1 / 2)\left\{\ln h_{t}\left(\boldsymbol{\theta}_{1}, \boldsymbol{\theta}_{2}\right)+\ln g_{t}\left(\boldsymbol{\theta}_{2}\right)\right\}-(1 / 2) \frac{\varepsilon_{t}^{2}}{h_{t}\left(\boldsymbol{\theta}_{1}, \boldsymbol{\theta}_{2}\right) g_{t}\left(\boldsymbol{\theta}_{2}\right)}
$$

The unconditional and the conditional variance components are estimated separately using maximization by parts. The iterative algorithm proceeds as follows:

Step 1: Maximize

$$
L_{T}^{U}\left(\boldsymbol{\theta}_{2}\right)=\sum_{t=1}^{T} \ell_{t}^{U}\left(\boldsymbol{\theta}_{2}\right)=-(1 / 2) \sum_{t=1}^{T}\left\{\ln g_{t}\left(\boldsymbol{\theta}_{2}\right)+\tilde{\varepsilon}_{t}^{2} / g_{t}\left(\boldsymbol{\theta}_{2}\right)\right\}
$$

with respect to $\boldsymbol{\theta}_{2}$, assuming $\tilde{\varepsilon}_{t}=\varepsilon_{t}$, that is, setting $h_{t}\left(\boldsymbol{\theta}_{1}, \boldsymbol{\theta}_{2}\right) \equiv 1$. Let the estimator of $\boldsymbol{\theta}_{2}$ be $\widehat{\boldsymbol{\theta}}_{2}^{(1)}$. Making use of $\widehat{\boldsymbol{\theta}}_{2}^{(1)}$, maximize

$$
L_{T}^{V}\left(\boldsymbol{\theta}_{1}, \widehat{\boldsymbol{\theta}}_{2}^{(1)}\right)=\sum_{t=1}^{T} \ell_{t}^{V}\left(\boldsymbol{\theta}_{1}, \widehat{\boldsymbol{\theta}}_{2}^{(1)}\right)=-(1 / 2) \sum_{t=1}^{T}\left\{\ln h_{t}\left(\boldsymbol{\theta}_{1}, \widehat{\boldsymbol{\theta}}_{2}^{(1)}\right)+\varepsilon_{t}^{* 2} / h_{t}\left(\boldsymbol{\theta}_{1}, \widehat{\boldsymbol{\theta}}_{2}^{(1)}\right)\right\}
$$

with respect to $\boldsymbol{\theta}_{1}$, where $\varepsilon_{t}^{*}=\varepsilon_{t} /\left\{g_{t}\left(\widehat{\boldsymbol{\theta}}_{2}^{(1)}\right)\right\}^{1 / 2}$. Denote the estimator as $\widehat{\boldsymbol{\theta}}_{1}^{(1)}$.

Step 2: Maximize

$$
L_{T}^{U}\left(\boldsymbol{\theta}_{2}\right)=\sum_{t=1}^{T} \ell_{t}^{U}\left(\boldsymbol{\theta}_{2}\right)=-(1 / 2) \sum_{t=1}^{T}\left\{\ln g_{t}\left(\boldsymbol{\theta}_{2}\right)+\tilde{\varepsilon}_{t}^{2} / g_{t}\left(\boldsymbol{\theta}_{2}\right)\right\}
$$


with respect to $\boldsymbol{\theta}_{2}$, where $\tilde{\varepsilon}_{t}=\varepsilon_{t} /\left\{h_{t}\left(\widehat{\boldsymbol{\theta}}_{1}^{(1)}, \widehat{\boldsymbol{\theta}}_{2}^{(1)}\right)\right\}^{1 / 2}$. Call this estimator $\widehat{\boldsymbol{\theta}}_{2}^{(2)}$ and maximize

$$
L_{T}^{V}\left(\boldsymbol{\theta}_{1}, \widehat{\boldsymbol{\theta}}_{2}^{(2)}\right)=\sum_{t=1}^{T} \ell_{t}^{V}\left(\boldsymbol{\theta}_{1}, \widehat{\boldsymbol{\theta}}_{2}^{(2)}\right)=-(1 / 2) \sum_{t=1}^{T}\left\{\ln h_{t}\left(\boldsymbol{\theta}_{1}, \widehat{\boldsymbol{\theta}}_{2}^{(2)}\right)+\varepsilon_{t}^{* 2} / h_{t}\left(\boldsymbol{\theta}_{1}, \widehat{\boldsymbol{\theta}}_{2}^{(2)}\right)\right\}
$$

with respect to $\boldsymbol{\theta}_{1}$, where $\varepsilon_{t}^{*}=\varepsilon_{t} /\left\{g_{t}\left(\widehat{\boldsymbol{\theta}}_{2}^{(2)}\right)\right\}^{1 / 2}$. This yields $\widehat{\boldsymbol{\theta}}_{1}^{(2)}$.

Iterate until convergence.

In the $n$th iteration, maximization is carried out in the usual way by solving the score equations:

$$
\frac{\partial}{\partial \boldsymbol{\theta}_{2}} L_{T}^{U}\left(\boldsymbol{\theta}_{2}\right)=(1 / 2) \sum_{t=1}^{T}\left(\frac{\tilde{\varepsilon}_{t}^{2}}{g_{t}\left(\boldsymbol{\theta}_{2}\right)}-1\right) \frac{1}{g_{t}\left(\boldsymbol{\theta}_{2}\right)} \frac{\partial g_{t}\left(\boldsymbol{\theta}_{2}\right)}{\partial \boldsymbol{\theta}_{2}}=0
$$

for $\boldsymbol{\theta}_{2}$ with $\tilde{\varepsilon}_{t}=\varepsilon_{t} /\left\{h_{t}\left(\widehat{\boldsymbol{\theta}}_{1}^{(n-1)}, \widehat{\boldsymbol{\theta}}_{2}^{(n-1)}\right)\right\}^{1 / 2}$, and

$$
\frac{\partial}{\partial \boldsymbol{\theta}_{1}} L_{T}^{V}\left(\boldsymbol{\theta}_{1}\right)=(1 / 2) \sum_{t=1}^{T}\left(\frac{\varepsilon_{t}^{* 2}}{h_{t}\left(\boldsymbol{\theta}_{1}, \widehat{\boldsymbol{\theta}}_{2}^{(n)}\right)}-1\right) \frac{1}{h_{t}\left(\boldsymbol{\theta}_{1}, \widehat{\boldsymbol{\theta}}_{2}^{(n)}\right)} \frac{\partial h_{t}\left(\boldsymbol{\theta}_{1}, \widehat{\boldsymbol{\theta}}_{2}^{(n)}\right)}{\partial \boldsymbol{\theta}_{1}}=0
$$

for $\boldsymbol{\theta}_{1}$, where $\varepsilon_{t}^{*}=\varepsilon_{t} /\left\{g_{t}\left(\widehat{\boldsymbol{\theta}}_{2}^{(n)}\right)\right\}^{1 / 2}$. Letting $G_{l t} \equiv G_{l}\left(t / T ; \gamma_{l}, \mathbf{c}_{l}\right), l=1, \ldots, r$, we have

$$
\frac{\partial g_{t}\left(\boldsymbol{\theta}_{2}\right)}{\partial \boldsymbol{\theta}_{2}}=\left(1, G_{1 t}, G_{1 t}^{(\gamma)}, G_{1 t}^{(c)}, \ldots, G_{r t}, G_{r t}^{(\gamma)}, G_{r t}^{(c)}\right)^{\prime}
$$

where, for $k=1$ in (8),

$$
\begin{aligned}
G_{l t}^{(\gamma)} & =\frac{\partial G_{l t}}{\partial \gamma_{l}}=\delta_{l} G_{l t}\left(1-G_{l t}\right)\left(t / T-c_{l}\right) \\
G_{l t}^{(c)} & =\frac{\partial G_{l t}}{\partial c_{l}}=-\gamma_{l} \delta_{l} G_{l t}\left(1-G_{l t}\right)
\end{aligned}
$$

and for $k>1$

$$
\begin{aligned}
G_{l t}^{(\gamma)} & =\frac{\partial G_{l t}}{\partial \gamma_{l}}=\delta_{l} G_{l t}\left(1-G_{l t}\right) \prod_{j=1}^{k}\left(t / T-c_{l j}\right) \\
G_{i l t}^{(c)} & =\frac{\partial G_{i l t}}{\partial c_{l}}=-\gamma_{l} \delta_{l} G_{l t}\left(1-G_{l t}\right) \prod_{j=1, j \neq l}^{k}\left(t / T-c_{l j}\right)
\end{aligned}
$$

where $c_{l j}$ denotes the $j$ th element in the parameter vector $\mathbf{c}_{l}, l=1, \ldots, r$, and

$$
\begin{aligned}
\frac{\partial h_{t}\left(\boldsymbol{\theta}_{1}, \widehat{\boldsymbol{\theta}}_{2}^{(n)}\right)}{\partial \boldsymbol{\theta}_{1}}= & \left(1, \varepsilon_{t-1}^{* 2}, \ldots, \varepsilon_{t-q}^{* 2}, \varepsilon_{t-1}^{* 2} I_{t-1}\left(\varepsilon_{t-1}^{*}<0\right), \ldots, \varepsilon_{t-q}^{* 2} I_{t-q}\left(\varepsilon_{t-q}^{*}<0\right),\right. \\
& \left.h_{t-1}\left(\boldsymbol{\theta}_{1}, \widehat{\boldsymbol{\theta}}_{2}^{(n)}\right), \ldots, h_{t-p}\left(\boldsymbol{\theta}_{1}, \widehat{\boldsymbol{\theta}}_{2}^{(n)}\right)\right)^{\prime}+\sum_{j=1}^{p} \beta_{j} \frac{\left.\partial h_{t-j}\left(\boldsymbol{\theta}_{1}, \widehat{\boldsymbol{\theta}}_{2}^{(n)}\right)\right)}{\partial \boldsymbol{\theta}_{1}}
\end{aligned}
$$

This algorithm is computationally attractive in the present situation where direct maximization of the log-likelihood function is difficult. Under certain regularity conditions, the resulting estimator coincides with the ML estimator and becomes fully efficient upon convergence; see Song, Fan, and Kalbfleisch (2005) for details. Throughout this paper, we assume that certain regularity conditions are satisfied to ensure consistency and asymptotic normality of the QML 
estimator. The asymptotic properties of the maximum likelihood estimators of the TV-GJRGARCH model have been established in Amado and Teräsvirta (2011).

In this work, the long time series requires some modifications to the estimation algorithm. Because the whole series is divided into non-overlapping subperiods, the different data segments can have different "baseline" volatility levels. For this reason, the algorithm iterates from an initial value which is estimated by "chain rule" to accommodate differences in the volatility levels. This proceeds as follows. First, for the first subperiod, estimate the parameters of $g_{1 t}=\delta_{0}+$ $\sum_{l=1}^{r_{1}} \delta_{1 l} G_{1 l}\left(t / T ; \gamma_{1 l}, \mathbf{c}_{1 l}\right)$ where $r_{1}$ is the number of transitions for this period. The estimate $\widehat{g}_{1 T}$ serves as the "intercept" in the nonstationary component of the next subperiod. Conditioning on this value, carry out the estimation of the parameters for the next subperiod. More generally, for the $i$ th subperiod, estimate $g_{i t}=\widehat{\delta}_{0}^{(i-1)}+\sum_{l=1}^{r_{i}} \delta_{i l} G_{i l}\left(t / T ; \gamma_{i l}, \mathbf{c}_{i l}\right)$ by conditioning on $\widehat{\delta}_{0}^{(i-1)}$, where $\widehat{\delta}_{0}^{(i-1)}=\widehat{\delta}_{0}+\sum_{l=1}^{r_{i-1}} \widehat{\delta}_{l} G_{l}\left(t / T ; \widehat{\gamma}_{l}, \widehat{\mathbf{c}}_{l}\right)$, such that $t=T$ is the last observation of the $(i-1)$ th subperiod and $r_{i-1}$ is the number of transitions in the same subperiod. The estimates $\widehat{\mathbf{c}}_{l}$ are then used as fixed values in the next iterations. This means that the estimation algorithm is carried out without iterating $\widehat{\mathbf{c}}_{l}$, and therefore the parameters $\widehat{\gamma}_{l}$ and $\delta_{l}, l=0, \ldots, r$, are estimated conditionally on those estimates.

Another aspect that deserves attention in the estimation of the model is the selection of starting-values of the time-varying parameters. Since the log-likelihood may contain several local maxima, it is advisable to initiate the estimation from different sets of starting-values before settling for the final parameter estimates. In addition, to improve the accuracy of the estimates of the standard errors, we follow Fiorentini, Calzolari, and Panattoni (1996) and use analytic first derivatives both in the estimation of the TV-GARCH models and in the computation of the test statistics. All computations in this paper have been carried out using the Ox programming language, version 6.10, see Doornik (2009).

\section{Application to the Dow Jones Industrial Average index}

\subsection{Data description}

In this section we apply our modelling procedure of the TV-GARCH model to the daily returns of the Dow Jones Industrial Average (DJIA) index. The entire sample covers the period between January 2, 1920 and May 31, 2011, yielding 22986 observations. The daily returns are defined as log differences of the closing prices of the index between two consecutive days. The closing prices of the DJIA index have been obtained from the Wharton Research Data Services (WRDS) provided by the Wharton School of the University of Pennsylvania. Descriptive statistics of the return series can be found in Table 1 . The coefficients of skewness and kurtosis seem to indicate that the stock returns $\varepsilon_{t}$ have a left skewed and a significantly fat-tailed distribution. To check this conclusion, we also provide the robust measures of skewness and kurtosis as recommended

Table 1: Summary statistics of the daily DJIA return series: full sample

\begin{tabular}{lcccccccc}
\hline \hline Series & Min & Max & Mean & S.D. & Skew & Ex.Kr. & Rob.Sk. & Rob.Kr. \\
\hline$\varepsilon_{t}$ & -25.63 & 14.27 & 0.021 & 1.144 & -0.591 & 23.82 & -0.007 & 0.245 \\
$\varepsilon_{t} / \widehat{g}_{t}^{1 / 2}$ & -23.55 & 8.88 & 0.025 & 0.883 & -1.092 & 26.44 & -0.005 & 0.147
\end{tabular}

Notes: The table contains summary statistics for the DJIA return series. The sample period starts in January 2, 1920 and ends in May 31, 2011 (22986 observations). 

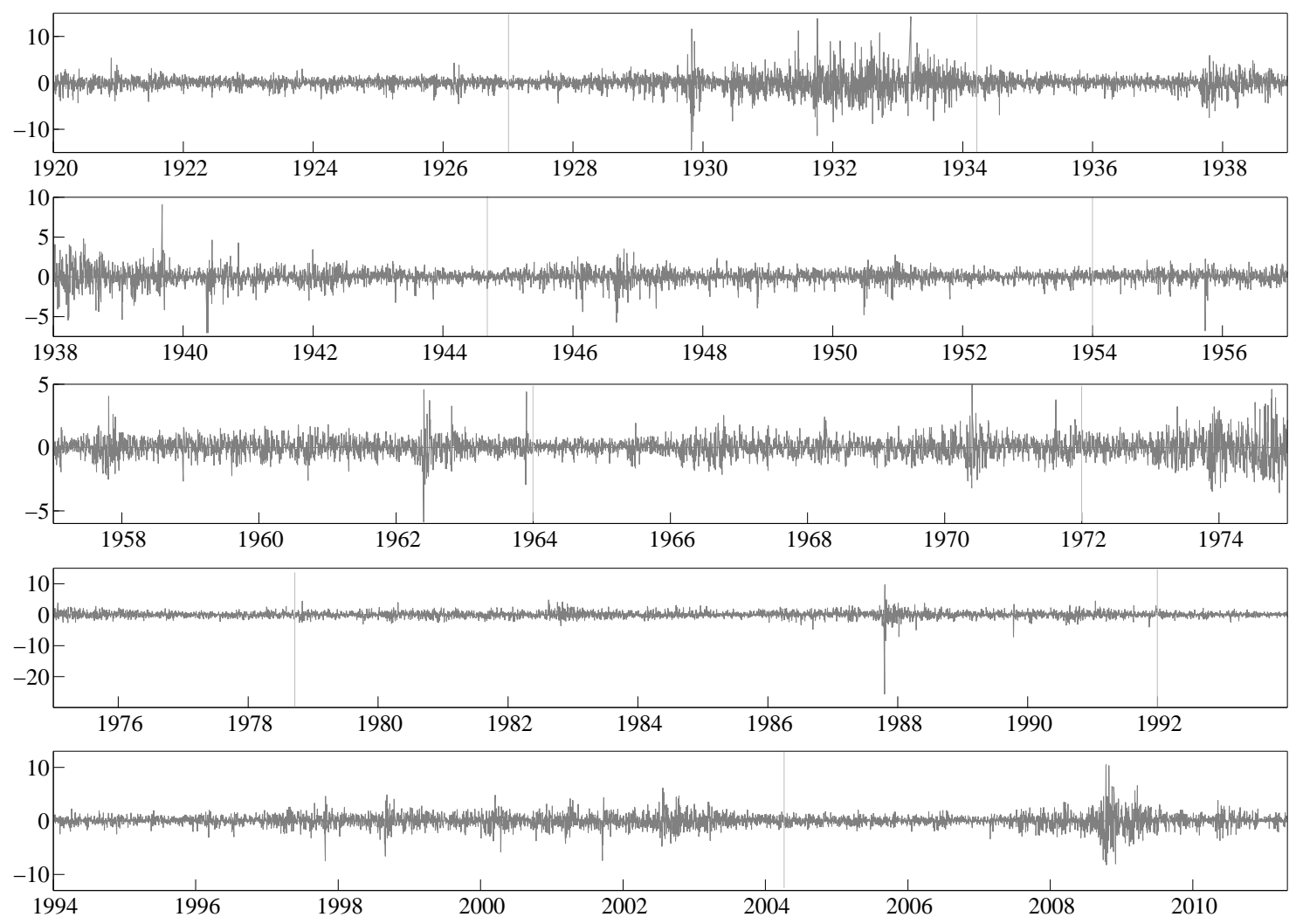

Figure 1: The DJIA daily returns from January 2, 1920 until May 31, 2011. The vertical lines represent the split dates.

by Kim and White (2004) in order to account for outliers. The robust measure for skewness is practically zero whereas the robust kurtosis measure, not surprisingly, suggests that there is excess kurtosis in the series. Figure 1 graphs the daily returns for the DJIA index for the observation period. The period covers the Great Depression of 1929 and the early 1930's, the Second World War, the 1973 oil crisis, the stock market crash of October 1987, the dot-com bubble, and the recent financial crisis. Because of the long observation period it is unlikely that the series is stationary. We divide the long return series into ten non-overlapping subperiods each comprising at least of 1500 observations. In most cases we report the findings for each of the ten subperiods and the full sample. Summary statistics of the subperiods can be found in Table 11.

\subsection{Estimation results}

The focus of the empirical analysis lies in the specification of the unconditional variance using the modelling strategy described in Section 2.2. We begin by determining the number of transitions for each subperiod separately. This is done using the sequence of specification tests. The initial significance level of the sequence of tests is $\alpha^{(1)}=0.05$. At each stage of the sequence we halve the significance level of the test, i.e. $\tau=0.5$. The tests results appear in the second column of Table 2.

We first test the hypothesis of constant unconditional variance against a smoothly timevarying unconditional variance with one transition function. The null hypothesis is rejected for all subperiods with two exceptions. The first one is subperiod 5, the post-World War II period from the mid-1950's until mid-1960's, and the second one subperiod 8 covering the October 1987 
crash. The stock market volatility returned to normal levels very quickly after the crash, which suggests that the unconditional variance remained stable during that period. These findings are consistent with the hypothesis of Engle and Lee (1999) that the 1987 crash is more transient than other big shocks. The null hypothesis of constant unconditional variance is, however, rejected very strongly for the subperiods $2,3,6,7,9$ and 10 . The second period contains the Great Depression, the third includes the Second World War, the seventh one the OPEC oil crisis, the ninth the IT bubble, and the most recent one the financial crisis. The results indicate that the strongest deterministic changes in the unconditional variance are associated with the largest economic recessions in the period under study.

The results from the sequence of nested tests based on (10) to select $k$ in (8) are given in the last three columns of Table 2, see Amado and Teräsvirta (2011) for details. The strongest rejection occurs when $k=1$ for six out of eight periods, subperiods 1 and 7 being the only exceptions. For subperiod 7 , the specification test sequence suggests a third-order polynomial for the transition function since $k=3$. We choose $k=1$, however, to simplify the specification and the estimation of the model for this subsample. Post-estimation misspecification tests then indicate the validity of this choice or reveal misspecification.

We first estimate a TV-GJR-GARCH model with a single transition and test against a double transition model at $\alpha^{(2)}=0.025$. We reject the hypothesis in four out of the eight subsamples and select $k=1$. Fitting the model with two transitions and testing for another transition yields for these subsamples $p$-values larger than $\alpha^{(3)}=0.0125$. Thus, we tentatively accept the model with two transitions as the final parameterization for the second, seventh, ninth and tenth subperiods. In particular, for subperiod 7 two transitions with $k=1$ are an adequate alternative, as could have been a single transition with $k=3$.

The above results imply that twelve transition functions in total are needed to describe the unconditional variance for the whole series. Estimation results for the TV-GJR-GARCH model are reported in Table 3, Panel $(a)$. The estimation results for each of the subperiods can be found in Tables 12-13.

Estimation is carried out with the sequential quadratic programming optimisation algorithm using analytical derivatives. The numbers in parenthesis below the parameter estimates are the asymptotic standard error estimates and calculated using numerical second derivatives. The standard errors of $\mathbf{c}_{i}, i=1, \ldots, 12$, are not available because the parameters $\delta_{j}, j=0$, and $\gamma_{j}, \ldots, 12$, are estimated conditionally on those parameters. In some subperiods we observe that the transition between the extreme regimes of volatility is quite rapid. For these cases, the maximum value of $\gamma_{j}$ is constrained to 300. This is done to save computation time due to slow convergence of the sequence of estimates for this parameter when $\gamma_{j}$ is very large. This approximation is adequate because the shape of the transition function changes very little after $\gamma_{j}$ exceeds 300. 
Table 2: $p$-values of sequences of Lagrange multiplier tests for the subsamples

\begin{tabular}{|c|c|c|c|c|}
\hline Subsamples & $\mathrm{H}_{0}$ & $\mathrm{H}_{03}$ & $\mathrm{H}_{02}$ & $\mathrm{H}_{01}$ \\
\hline \multicolumn{5}{|l|}{ Single transition } \\
\hline Subsample 1 & 0.0058 & 0.1738 & 0.0166 & 0.0895 \\
\hline Subsample 2 & $9 \times 10^{-5}$ & 0.8545 & 0.0070 & $2 \times 10^{-4}$ \\
\hline Subsample 3 & $2 \times 10^{-4}$ & 0.4117 & 0.0111 & $5 \times 10^{-4}$ \\
\hline Subsample 4 & 0.0047 & 0.1943 & 0.0431 & 0.0073 \\
\hline Subsample 5 & 0.6093 & 0.5998 & 0.8956 & 0.2156 \\
\hline Subsample 6 & $1 \times 10^{-4}$ & 0.1148 & 0.0599 & $1 \times 10^{-4}$ \\
\hline Subsample 7 & $6 \times 10^{-5}$ & $4 \times 10^{-6}$ & 0.3551 & 0.6931 \\
\hline Subsample 8 & 0.3627 & 0.4535 & 0.4366 & 0.1545 \\
\hline Subsample 9 & $1 \times 10^{-6}$ & 0.0072 & 0.0028 & $2 \times 10^{-4}$ \\
\hline Subsample 10 & $2 \times 10^{-5}$ & 0.0086 & 0.0308 & 0.0034 \\
\hline \multicolumn{5}{|l|}{ Double transition } \\
\hline Subsample 1 & 0.0902 & 0.0150 & 0.8754 & 0.4586 \\
\hline Subsample 2 & 0.0090 & 0.1824 & 0.0812 & 0.0092 \\
\hline Subsample 3 & 0.3066 & 0.4731 & 0.9733 & 0.0785 \\
\hline Subsample 4 & 0.0841 & 0.0315 & 0.7371 & 0.1667 \\
\hline Subsample 5 & - & - & - & - \\
\hline Subsample 6 & 0.1511 & 0.1998 & 0.5611 & 0.0683 \\
\hline Subsample 7 & 0.0063 & 0.0046 & 0.6733 & 0.0411 \\
\hline Subsample 8 & - & - & - & - \\
\hline Subsample 9 & 0.0014 & 0.0102 & 0.0110 & 0.1077 \\
\hline Subsample 10 & 0.0106 & 0.0199 & 0.8747 & 0.0162 \\
\hline \multicolumn{5}{|l|}{ Triple transition } \\
\hline Subsample 1 & - & - & - & - \\
\hline Subsample 2 & 0.0147 & 0.3739 & 0.6801 & 0.0020 \\
\hline Subsample 3 & - & - & - & - \\
\hline Subsample 4 & - & - & - & - \\
\hline Subsample 5 & - & - & - & - \\
\hline Subsample 6 & - & - & - & - \\
\hline Subsample 7 & 0.2204 & 0.0411 & 0.7332 & 0.7265 \\
\hline Subsample 8 & - & - & - & - \\
\hline Subsample 9 & 0.1681 & 0.6813 & 0.1199 & 0.1163 \\
\hline Subsample 10 & 0.0305 & 0.0289 & 0.0972 & 0.2368 \\
\hline
\end{tabular}

Notes: The entries are the $p$-values of the LM-type tests of constant unconditional variance against a time-varying GARCH model for each subperiod of the DJIA stock index returns. The test sequence starts at the significance level $\alpha=0.05$ and setting $\tau=0.5$. The order $k$ in (8) is chosen from the sequence of nested tests based on (10). If $\mathrm{H}_{0 i}$ is rejected most strongly, measured by the $p$-value, of the three hypotheses, one selects $k=i$. See Amado and Teräsvirta (2011) for further details. 
Table 3: Estimation results for the DJIA returns: full sample

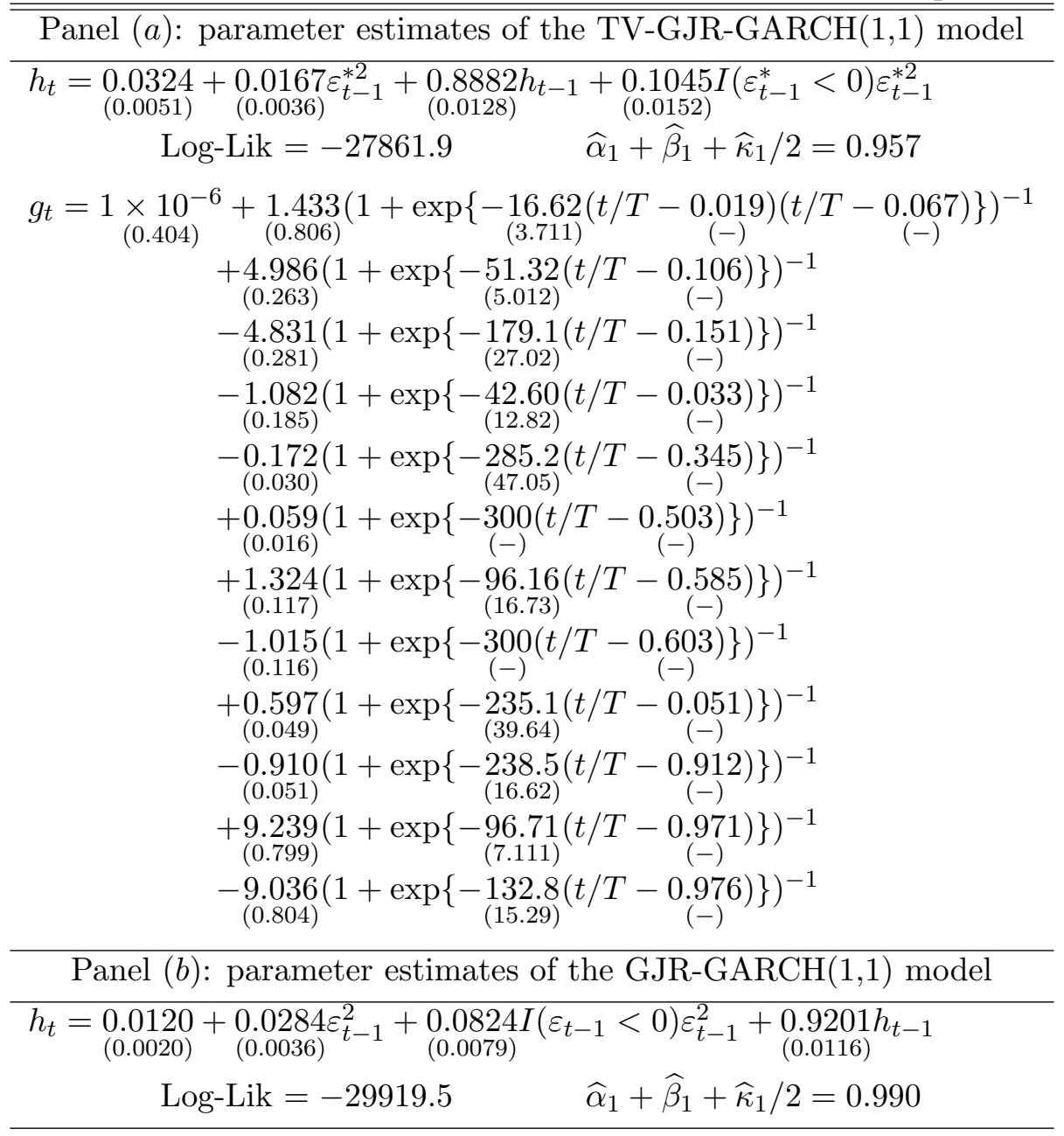

To see how the unconditional variance changes over time, the estimated component $g_{t}^{1 / 2}$ is plotted in the top panel of Figure 2. The estimated $g_{t}$ functions for each subperiod are shown in Figure 6. It is seen that the largest deterministic changes in the unconditional variance occur during recessions. In particular, the strongest movement in the long-run volatility is observed during the Great Depression. This is in agreement with Mikosch and Stărică (2004) who find that most of the recessions coincide with an increase in the unconditional variance of the series. In their analysis of the S\&P 500 returns, they identify the 1973 oil crisis as the major change detected in the unconditional variance, but then their time series only covers the period from January 2, 1953, to December 31, 1990.

For comparison, we also report the results of fitting the GJR-GARCH $(1,1)$ model into the complete series. They can be found in Panel $(b)$ of Table 3. The results for each subperiod appear in Table 14. We find that the subperiods characterized by the largest changes in the unconditional variance have a stronger integrated GJR-GARCH effect. The stationary condition for the full sample model is $\alpha_{1}+\beta_{1}+\kappa_{1} / 2<1$. The estimated model is practically an integrated GJR-GARCH model as the persistence indicator $\widehat{\alpha}_{1}+\widehat{\beta}_{1}+\widehat{\kappa}_{1} / 2=0.990$. The autocorrelation functions of $\left|\varepsilon_{t}\right|$ plotted in Figure 3 (upper panel) lead to the same conclusion. The graph clearly displays the long-memory property: relatively rapid decay at short lags followed by positive autocorrelations around a stable level at long lags. On the contrary, the autocorrelations of $\left|\varepsilon_{t}\right| / \widehat{g}_{t}^{1 / 2}$, plotted in the lower panel of Figure 3, decay very quickly with the lag length and only 

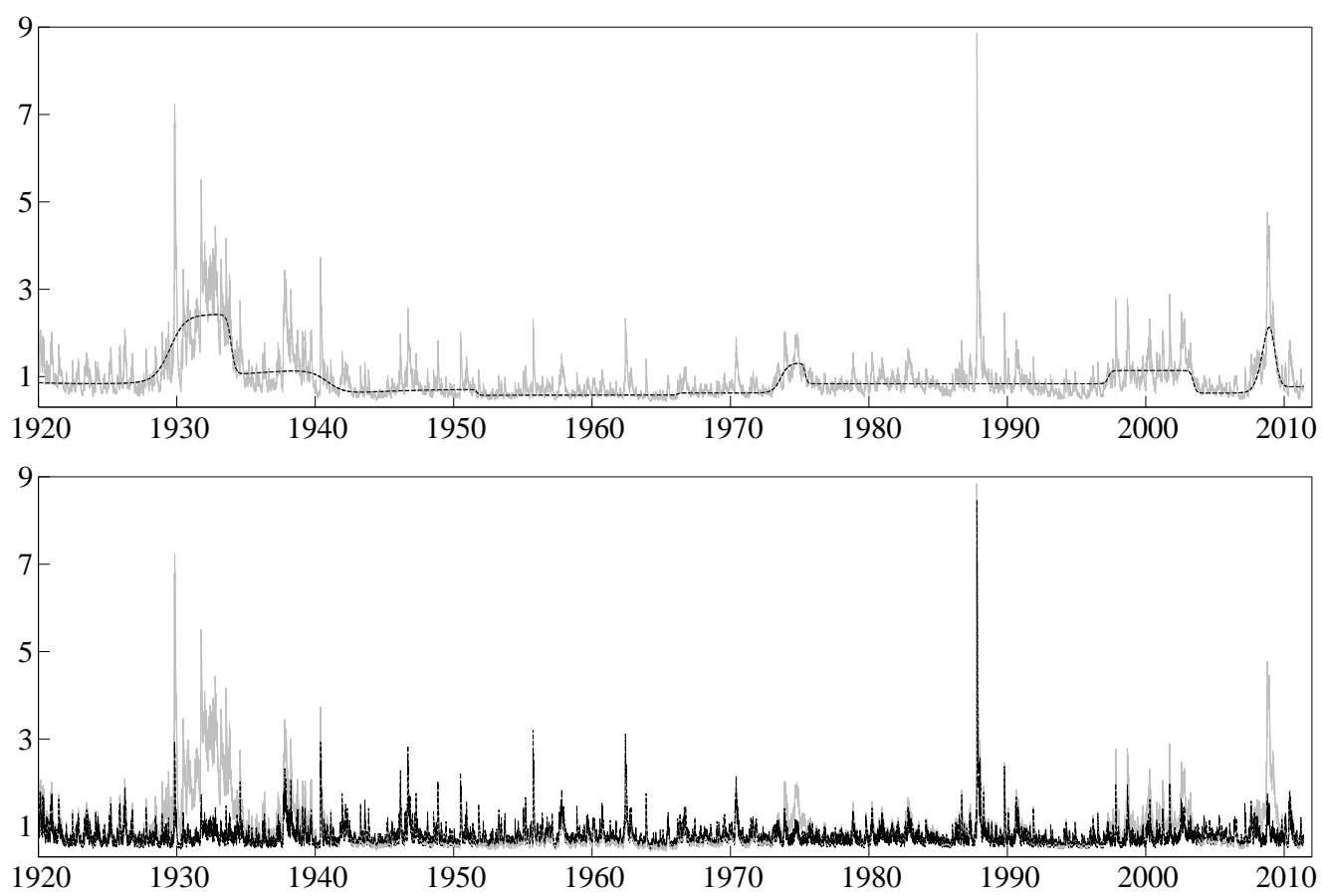

Figure 2: First panel, shows the estimated function $g_{t}^{1 / 2}$ (black curve) and the conditional standard deviation from the GJR-GARCH(1,1) model (grey curve). Second panel, shows the estimated conditional standard deviations from the GJR-GARCH $(1,1)$ model (grey curve) and from the TV-GJR-GARCH(1,1) (black curve) models.

the first 70 autocorrelation estimates or so are significantly different from zero judging from the $95 \%$ confidence bounds drawn under the assumption that the errors are normal and independent. The decay rate is rapid in the beginning but does contain a 'plateau' between, say, lags 75 and 200. The persistence indicator now equals 0.957 . The results show that modelling the changes in the unconditional variance strongly reduces the amount of evidence for long-memory. This can also be seen from the Geweke and Porter-Hudak (1983) (GPH) estimates of the long-memory parameter in Table 4. Of course, the GPH parameter estimates vary with the bandwidth but, overall, the table indicates that the daily DJIA return series is either nonstationary (for the bandwidth choices $m=T^{0.4}$ and $m=T^{0.5}$ ) or is very close to the nonstationary region (for $\left.m=T^{0.6}\right)$. However, when the movements in the unconditional variance component are taken into account the GPH estimates have the remarkable low values of $0.1004,0.1686$ and 0.2657 for these three bandwidths.

Table 4: GPH estimates of the long-memory parameter: full sample

\begin{tabular}{cccc}
\hline \hline & $d_{G P H}\left(m=T^{0.4}\right)$ & $d_{G P H}\left(m=T^{0.5}\right)$ & $d_{G P H}\left(m=T^{0.6}\right)$ \\
\hline$\varepsilon_{t}$ & 0.7440 & 0.5372 & 0.4746 \\
$\varepsilon_{t} / \widehat{g}_{t}^{1 / 2}$ & $(0.0825)$ & $(0.0545)$ & $(0.0312)$ \\
& 0.1004 & 0.1686 & 0.2657 \\
& $(0.1069)$ & $(0.0569)$ & $(0.0324)$ \\
\hline
\end{tabular}

Notes: The numbers in parentheses are the standard errors. The bandwidth $m$ equals $T^{\alpha}, \alpha \in\{0.4,0.5,0.6\}$ where $T$ is the number of observations.

A similar conclusion can be reached by looking at the estimated conditional at the estimated 

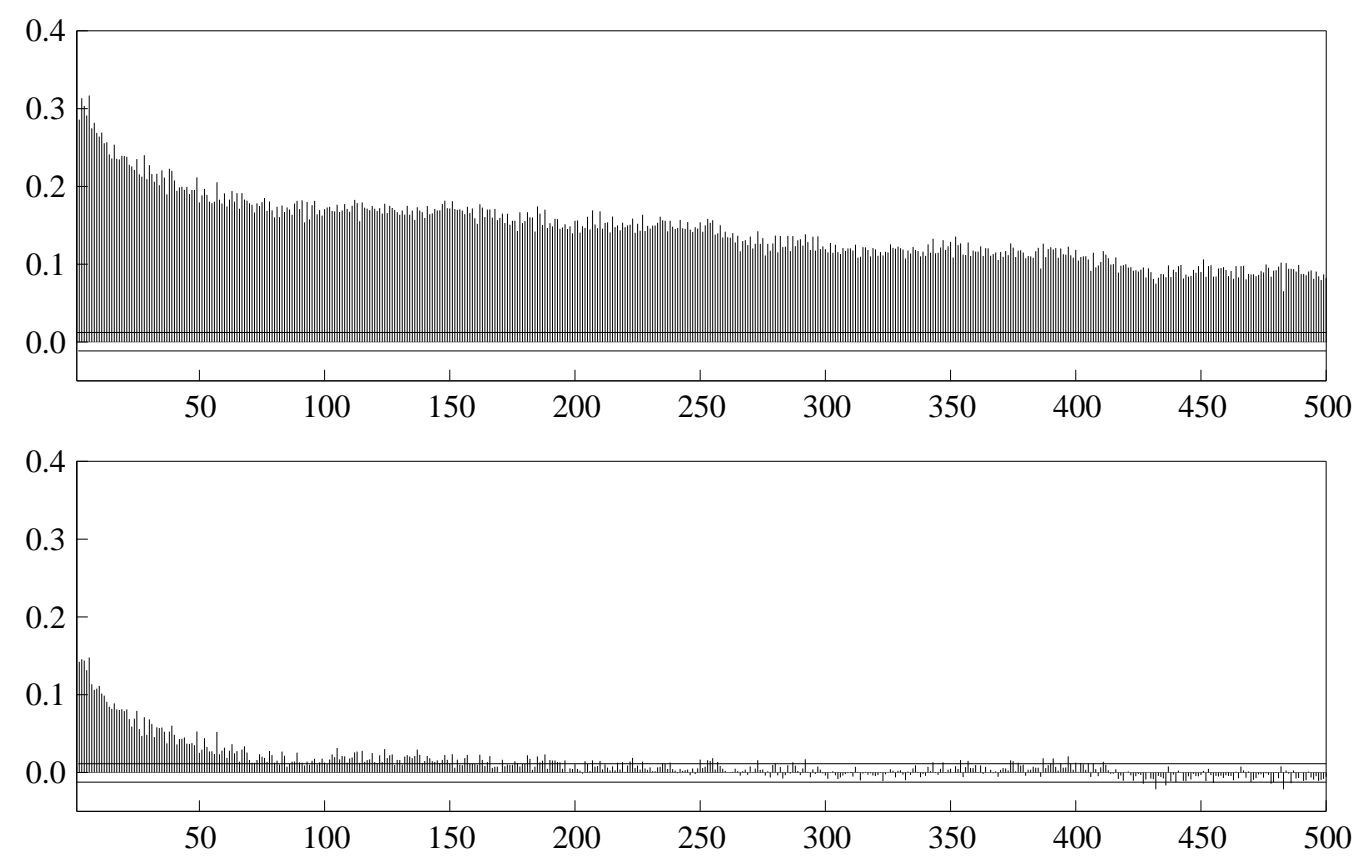

Figure 3: Top panel: the sample autocorrelation functions of the absolute values of the DJIA daily returns. Bottom panel: the sample autocorrelation functions of the standardized variable $\left|\varepsilon_{t}\right| / \widehat{g}_{t}^{1 / 2}$. The horizontal line in both panels is the corresponding $95 \%$ confidence interval under the iid normality assumption.

conditional standard deviations from the GJR-GARCH(1,1) model of $\varepsilon_{t}$ and $\varepsilon_{t} / \widehat{g}_{t}^{1 / 2}$. The bottom panel of Figure 2 displays both series. The (almost) stationary behaviour of the conditional standard deviation of $\varepsilon_{t} / \widehat{g}_{t}^{1 / 2}$ (black curve) contrasts with the nonstationary behaviour of the conditional standard deviation of $\varepsilon_{t}$ (grey curve). It shows that the conditional variance of $\varepsilon_{t} / \widehat{g}_{t}^{1 / 2}$ is considerably smaller than that of $\varepsilon_{t}$ from the GJR-GARCH $(1,1)$ model. For illustration, we also show in Figure 7 the estimated conditional standard deviations generated from both models separately for each subperiod.

Table 5: $p$-values of the test of no ARCH in GARCH

\begin{tabular}{lccccc}
\hline \multirow{2}{*}{\multicolumn{1}{c}{ Model }} & \multicolumn{5}{c}{ Lag order } \\
\cline { 2 - 6 } & 1 & 2 & 3 & 4 & 5 \\
\hline GJR-GARCH(1,1) & 0.398 & 0.368 & 0.559 & 0.721 & 0.810 \\
TV-GJR-GARCH(1,1) & 0.890 & 0.292 & 0.476 & 0.644 & 0.775 \\
\hline
\end{tabular}

The adequacy of the estimated TV-GJR-GARCH $(1,1)$ model is checked using the diagnostic tests proposed by Amado and Teräsvirta (2011). We perform tests against remaining ARCH in the standardized residuals, TV-GJR-GARCH $(1,2)$ and TV-GJR-GARCH $(2,1)$ models, and ST-GJR-GARCH $(1,1)$ model of order 1 . The $p$-values of the tests are given in Tables 5 and 6. For comparison we also show the test results for the estimated GJR-GARCH(1,1) model. The results indicate no evidence of remaining $\mathrm{ARCH}$ in the standardized residuals, nor can one argue in favour of higher-order TV-GJR-GARCH models; see Tables 5 and 6 . However, the TVGJR-GARCH(1,1) model is strongly rejected against ST-GJR-GARCH(1,1) model. This result 
suggests that the TV-GJR-GARCH(1,1) model is not yet an adequate parameterization, and a nonlinear GARCH model instead of the GJR-GARCH variant could improve the specification. Modelling the short-run dynamics of volatility of a long time series would thus need more work. Nevertheless, because the focus of this paper is on the modelling of changes in the long-run volatility component, refinements in the modelling of $h_{t}$ are left for further work.

Table 6: $p$-values of tests against models of higher orders and against a nonlinear structure

\begin{tabular}{lccc}
\hline \hline \multirow{2}{*}{ Model } & \multicolumn{3}{c}{ Alternative model } \\
\cline { 2 - 4 } & GJR $(1,2)$ & GJR $(2,1)$ & ST-GJR $(k=1)$ \\
\hline GJR-GARCH $(1,1)$ & 0.0065 & 0.0118 & $4 \times 10^{-7}$ \\
TV-GJR-GARCH $(1,1)$ & 0.7118 & 0.1407 & 0.0022 \\
\hline
\end{tabular}

\subsection{Forecasting comparison}

To evaluate the forecasting performance of the estimated TV-GJR-GARCH model we compare its out-of-sample forecasts with those of the GJR-GARCH model. The out-of-sample evaluation sample spans the period from June 1, 2011 through November 30, 2011, which amounts to 128 observations. The post-sample forecast comparisons are carried out as follows. First, in order to evaluate the predictive ability of the competing models, the daily squared returns are used as a proxy for the latent volatility. Second, to evaluate the accuracy of the forecasts, the models are re-estimated using both the full sample $(T=22986)$ and the eight subperiods with timevarying unconditional variance. The in-sample and out-of-sample periods for each subsample are presented in Table 16. Finally, we summarize the forecasting performance by computing the Mean Absolute Forecast Error (MAFE) and Root Mean Squared Forecast Error (RMSFE) for the competing models. To reduce the impact of outlying observations on forecasting evaluation, we also consider the Median Squared Forecast Error (MedSFE).

Table 7: Out-of-sample prediction accuracy for the full sample

\begin{tabular}{ccccccc}
\hline \hline & \multicolumn{3}{c}{ GJR-GARCH } & \multicolumn{3}{c}{ TV-GJR-GARCH } \\
\cline { 2 - 7 } Horizons & MedSFE & MAFE & RMSFE & MedSFE & MAFE & RMSFE \\
\hline$h=1$ & 3.795 & 2.763 & 4.649 & 2.233 & 2.620 & 4.602 \\
$h=5$ & 3.436 & 2.908 & 5.154 & 1.999 & 2.719 & 5.110 \\
$h=10$ & 2.391 & 2.989 & 5.373 & 1.247 & 2.736 & 5.322 \\
$h=20$ & 3.347 & 3.117 & 5.585 & 1.343 & 2.912 & 5.589 \\
$h=60$ & 3.379 & 2.588 & 3.689 & 0.801 & 2.449 & 3.865 \\
$h=90$ & 0.934 & 2.476 & 3.925 & 0.565 & 2.495 & 4.050 \\
\hline
\end{tabular}

Notes: The out-of-sample forecast evaluation statistics are the Median Squared Forecast Error (MedSFE), Mean Absolute Forecast Error (MAFE) and the Root Mean Squared Forecast Error (RMSFE) criteria.

Results are presented in Tables 7 and 9 for forecasting horizons from one to 90-days-ahead forecasts. For the full sample, the results in Table 7 indicate that for short-term horizons the TV-GJR-GARCH model outperforms the GJR-GARCH model based on the RMSE loss function. For horizons longer than 60 days the GJR-GARCH model performs better than the TV-GJR-GARCH model. If we instead consider MedSFE as a measure of predictive ability, the forecasting accuracy of the TV-GJR-GARCH model is superior to that of the GJR-GARCH model both for short-term and long-term forecasts. This suggests that the TV-GJR-GARCH model may generate a number of exceptionally inaccurate forecasts that strongly affect the 


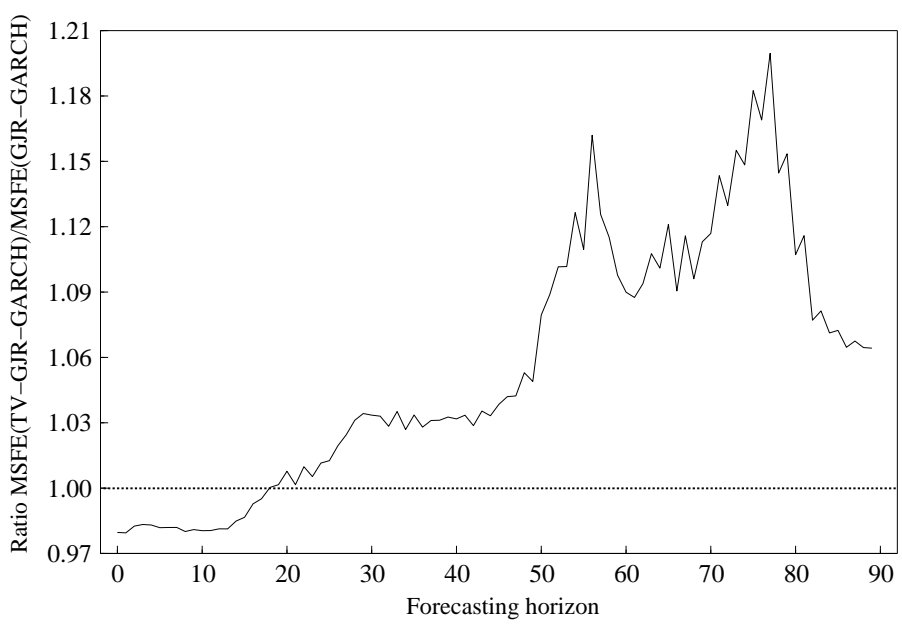

Figure 4: Out-of-sample forecasting comparison between GJR-GARCH e TV-GJR-GARCH models for the full sample.

RMSFE. The situation is also illustrated in Figure 4 that contains MSFE ratios of these two models for different forecast horizons. The ratio exceeds one, indicating superiority of the GJRGARCH model, at all horizons longer than 18 trading days. An obvious conclusion is that while changing unconditional variance is nicely described by a set of deterministic transitions, the assumption of a constant parameter conditional variance GARCH component over the whole period is too inflexible and should be relaxed.

This is illustrated by re-estimating the model using just the last 1799 observations that form subsample 10. The forecasts from that model are vastly superior to the corresponding ones from the GJR-GARCH model estimated for the same period. This is seen from the last three columns of Table 9. We repeat the same out-of-sample forecasting exercise with the same number of forecasts for the other subsamples. Table 9 shows that the TV-GJR-GARCH model generates more accurate forecasts than the GJR-GARCH model in all eight cases. The MSFE ratios in Figure 5 illustrate this. The ratios lie only modestly below unity for subperiods 3 and 4 , whereas the differences in precision are particularly dramatic in forecasting observations following subperiod 2 that contains data from the Great Depression and subperiod 7 that covers the 1973 oil crisis. This shows that taking care of the unconditional variance component is important even in models based on relatively short time series. It should be added, however, that what is being forecast is an 'after-crisis' period and that different results may be obtained in forecasting amidst a crisis of just before a beginning of a turbulent period.

Finally, we compute the out-of-sample F-type test statistic of McCracken (2007) which is designed to compare the relative forecasting performance of two nested models. The null hypothesis of the test is equal forecast accuracy. The OOS- $F$ statistic for $h$-step ahead forecasts is defined as

$$
\text { OOS- } F=(P-h+1) \frac{M S F E_{1}-M S F E_{2}}{M S F E_{2}}
$$

where $P$ is the number of out-of-sample observations, $M S F E_{1}$ is the Mean Square Forecasting Error of the restricted model and $M S F E_{2}$ is the Mean Square Error of the unrestricted model. If there is no difference in the forecast accuracy of the two models (the null hypothesis), the OOS- $F$ statistic should have a small value. The limiting distribution of the OOS- $F$ test is non-standard when the forecasts are nested under the null hypothesis. The asymptotic critical values of the test are tabulated in McCracken (2007). 


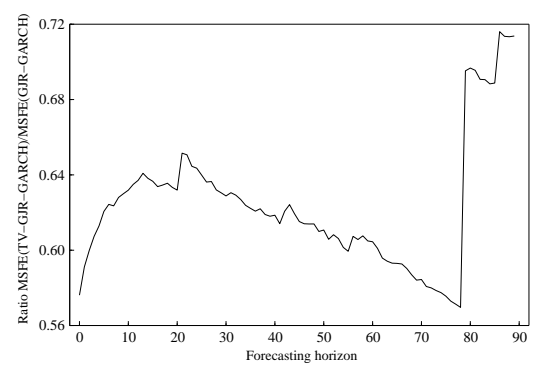

(a) Subperiod 1

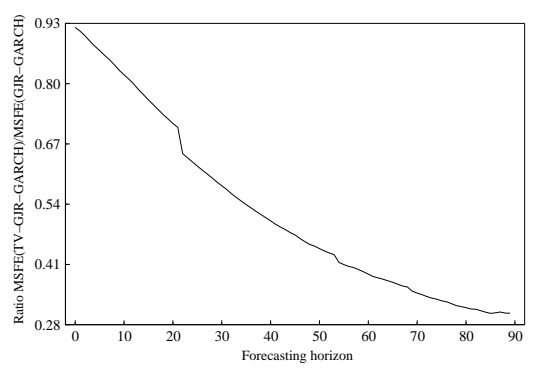

(c) Subperiod 3

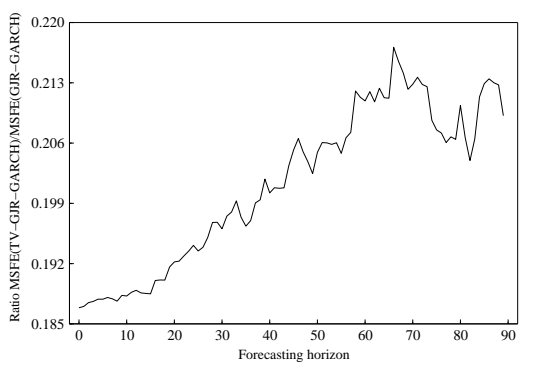

(e) Subperiod 6

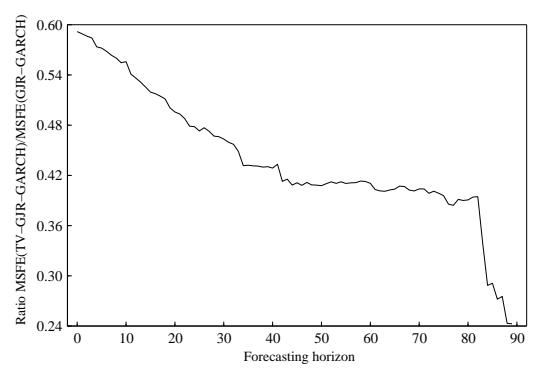

(g) Subperiod 9

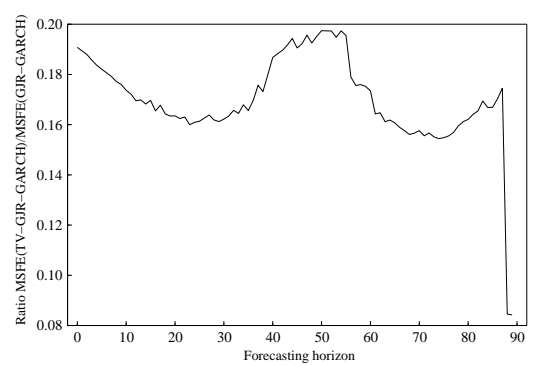

(b) Subperiod 2

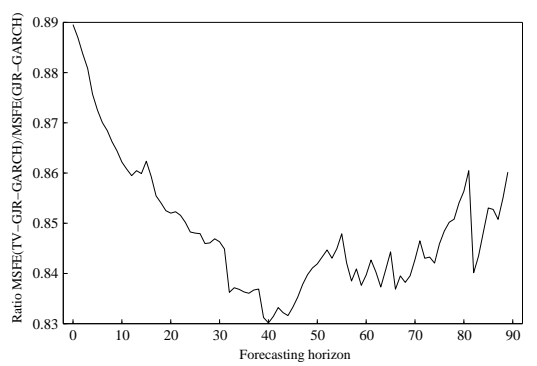

(d) Subperiod 4

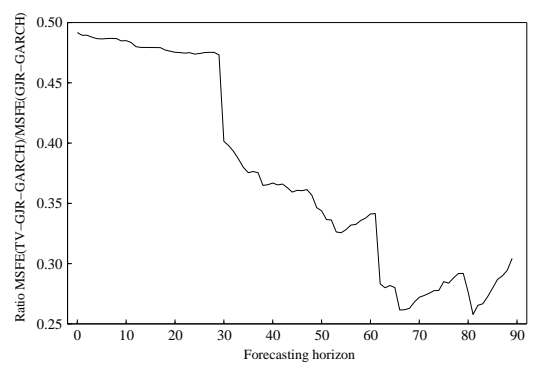

(f) Subperiod 7

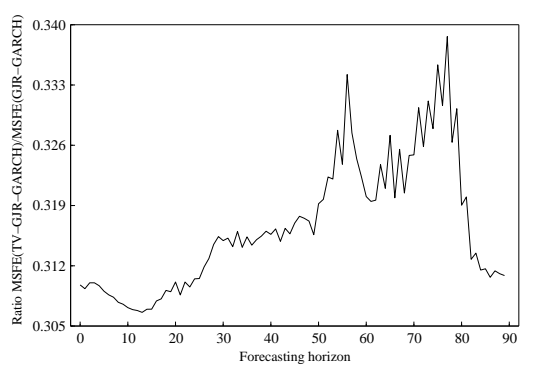

(h) Subperiod 10

Figure 5: Out-of-sample forecasting comparison between GJR-GARCH and TV-GJR-GARCH models for the eight subperiods. 


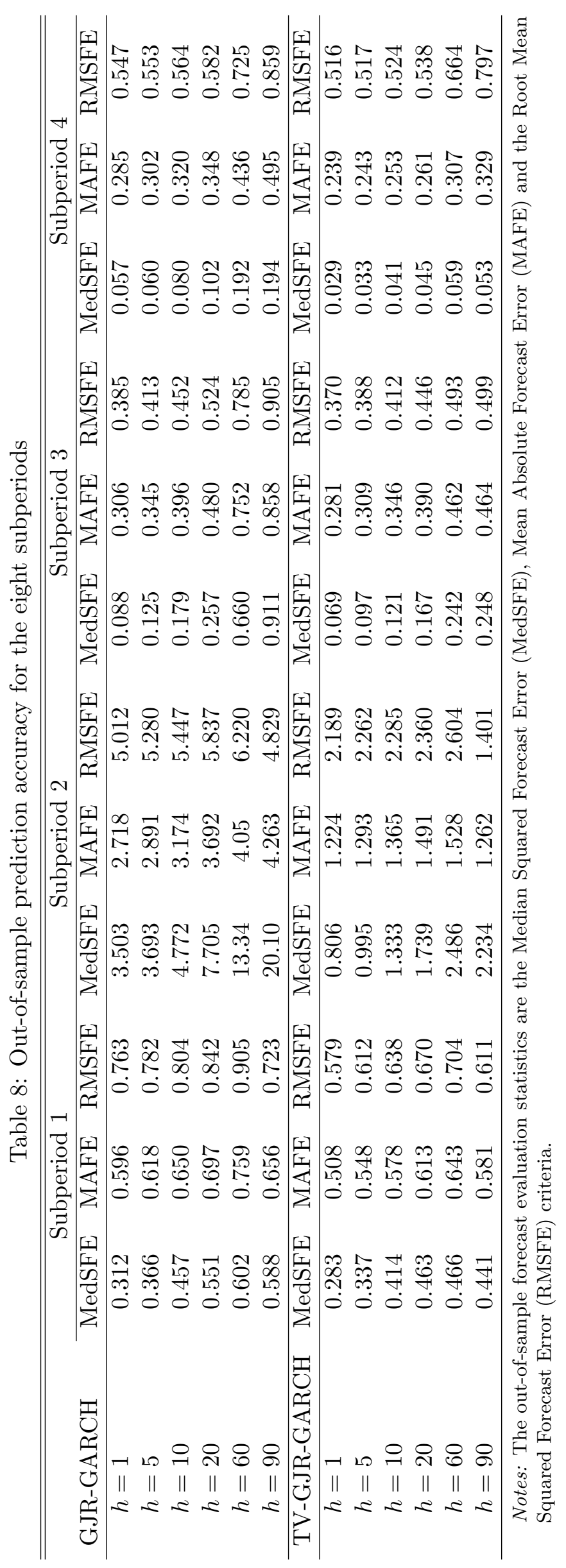




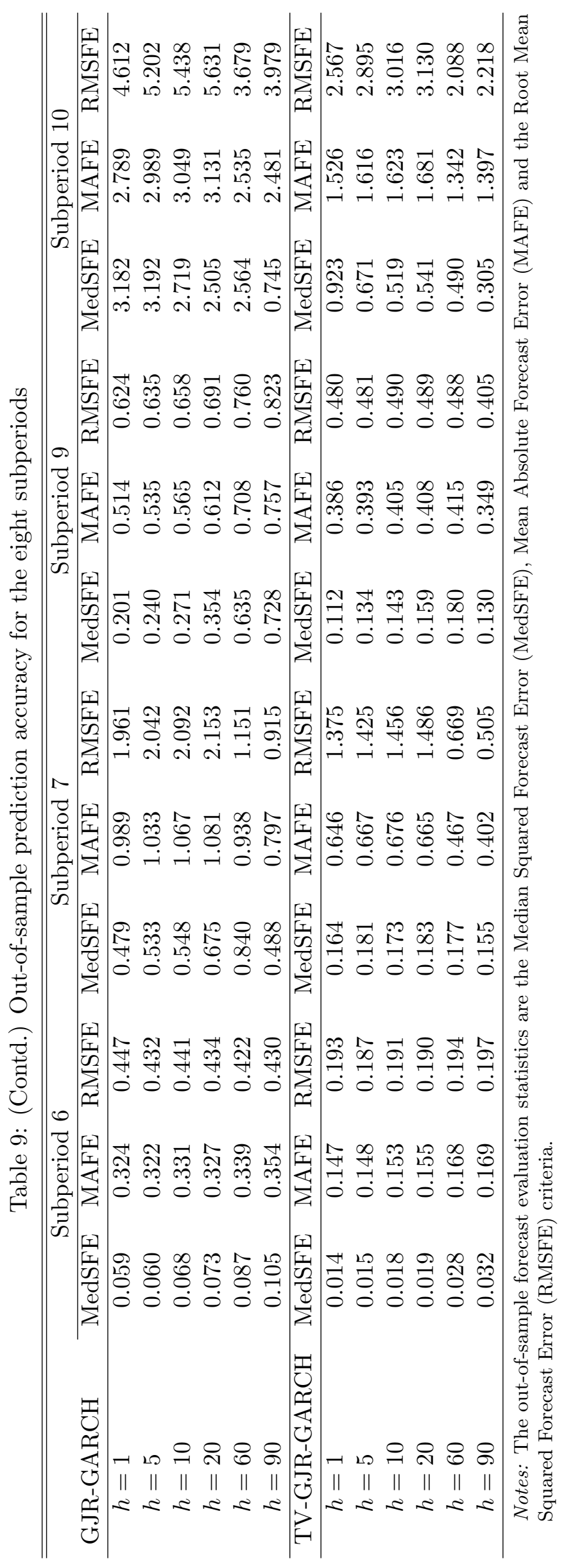


Results from the OOS- $F$ test statistic are presented in Table 10. For the full sample, the OOS- $F$ test fails to reject the null hypothesis of equal forecast accuracy at all horizons. Nevertheless, by omitting the older observations and using solely the observations of the subsample 10, the test supports the superiority of the TV-GJR-GARCH over the GJR-GARCH model at all horizons. Similarly, the null hypothesis of equal forecast accuracy is rejected at the 5 percent level for the remaining seven subperiods. Accordingly, the TV-GJR-GARCH model improves the accuracy of forecasts at all forecast horizons for forecasts from models based on the eight subsamples.

Table 10: Values of the OOS-F test statistic of predictive accuracy

\begin{tabular}{lrrrrrr}
\hline \hline & \multicolumn{6}{c}{ Horizons } \\
\cline { 2 - 7 } Subsamples & $h=1$ & $h=5$ & $h=10$ & $h=20$ & $h=60$ & $h=90$ \\
\hline Full sample & $\mathbf{2 . 6 6}$ & $\mathbf{2 . 1 4}$ & $\mathbf{2 . 3 1}$ & $\mathbf{- 0 . 1 7}$ & $\mathbf{- 6 . 1 4}$ & $\mathbf{- 2 . 3 5}$ \\
Subsample 1 & 91.96 & 76.42 & 68.12 & 61.36 & 43.10 & 14.44 \\
Subsample 2 & 542.84 & 551.35 & 557.13 & 557.96 & 324.69 & 424.08 \\
Subsample 3 & 10.78 & 16.49 & 24.12 & 40.81 & 102.97 & 84.37 \\
Subsample 4 & 15.52 & 17.18 & 18.19 & 18.34 & 12.79 & 5.85 \\
Subsample 6 & 552.60 & 503.60 & 508.62 & 455.65 & 253.78 & 143.66 \\
Subsample 7 & 129.23 & 127.62 & 123.27 & 116.57 & 129.40 & 82.30 \\
Subsample 9 & 86.90 & 90.70 & 93.97 & 106.73 & 95.33 & 115.46 \\
Subsample 10 & 285.20 & 276.41 & 267.94 & 243.76 & 145.07 & 86.46 \\
\hline
\end{tabular}

Notes: The OOS-F test statistics are computed for $h$-step ahead forecasts from the estimated GJR-GARCH and TV-GJR-GARCH models. The asymptotic critical values are tabulated in McCracken (2007). The numbers in boldface indicate a non-rejection of the null hypothesis of equal forecast accuracy at 5 percent level.

\section{Conclusions}

In this paper we develop a testing and modelling procedure for describing the long-term movements in daily stock market returns over excessively long time periods. This is done by multiplicatively decomposing the variance of a GARCH model into a conditional and an unconditional component, in which the unconditional variance is allowed to change smoothly over time. The proposed model is the Time-Varying GARCH model as in Amado and Teräsvirta (2011). The model building strategy relies on statistical inference, making use of a sequence of Lagrangemultiplier type specification tests. Because of the length of the observation period, the time series is divided into non-overlapping subperiods with the aim of alleviating the model building procedure. This makes it quite easy to model very long return series using techniques that have already been successfully applied to considerably shorter series.

An empirical example applied to the long daily DJIA return series shows how the technique works in practice. Our results suggest that the dependence structure of the series is well explained by deterministic changes in the unconditional variance, whereas the standard hypothesis of constant unconditional variance turns out to be inappropriate. Based on the diagnostic tests, we claim that the nonstationary TV-GJR-GARCH model should be preferred to the stationary model in applications to long financial time series.

Out-of-sample forecasts suggest that forecasting accuracy can be improved by using the TV-GJR-GARCH model instead of the GJR-GARCH model for short-term horizons. The TVGJR-GARCH model provides reasonably accurate short-term forecasts due to the flexible un- 
conditional variance component. Omitting the old observations and using solely the most recent observations to specify and estimate the model show that forecasts from the TV-GJR-GARCH model are superior to ones from the GJR-GARCH model at all forecast horizons.

Finally, the results indicate that the first-order GJR-GARCH model inadequately describes the short-run volatility dynamics in long return series, and that another type of nonlinear model should be considered. Further improvements in the modelling of the conditional variance over long time series are called for, but this problem is left for further research. 


\section{References}

Amado, C., And T. Teräsvirta (2011): "Modelling Volatility with Variance Decomposition," CREATES Research Paper 2011-1, Aarhus University.

Baillie, R. T., T. Bollerslev, and H. O. Mikkelsen (1996): "Fractionally Integrated Generalized Autoregressive Conditional Heteroskedasticity," Journal of Econometrics, 74, 330.

Baillie, R. T., and C. Morana (2009): "Modeling Long Memory and Structural Breaks in Conditional Variances: An Adaptive FIGARCH Approach," Journal of Economic Dynamics and Control, 33, 1577-1592.

Bollerslev, T. (1986): "Generalized Autoregressive Conditional Heteroskedasticity," Journal of Econometrics, 31, 307-327.

Brownlees, C. T., and G. M. Gallo (2010): "Comparison of Volatility Measures: A Risk Management Perspective," Journal of Financial Econometrics, 8, 29-56.

Diebold, F. X. (1986): "Comment on 'Modelling the Persistence of Conditional Variance', by R. F. Engle and T. Bollerslev," Econometric Reviews, 5, 51-56.

Doornik, J. A. (2009): An Object-Oriented Matrix Language Ox 6. London: Timberlake Consultants Press and Oxford: www.doornik.com.

Engle, R. F., and J. Gonzalo Rangel (2008): "The Spline-GARCH Model for LowFrequency Volatility and its Global Macroeconomic Causes," Review of Financial Studies, $21,1187-1222$.

Engle, R. F., And G. G. J. Lee (1999): "A Long-Run and Short-Run Component Model of Stock Return Volatility," in Cointegration, Causality, and Forecasting: A Festschrift in Honour of Clive W. J. Granger, ed. by R. F. Engle, and H. White, pp. 475-497. Oxford University Press.

Fiorentini, G., G. Calzolari, and L. Panattoni (1996): "Analytic Derivatives and the Computation of GARCH Estimates," Journal of Applied Econometrics, 11, 399-417.

Gallant, R. (1984): "The Fourier Flexible Form," American Journal of Agricultural Economics, 66, 204-208.

Geweke, J., and S. Porter-Hudak (1983): "The Estimation and Application of LongMemory Time-Series Models," Journal of Time Series Analysis, 4, 221-238.

Glosten, L. R., R. Jagannathan, and D. E. Runkle (1993): "On the Relation Between the Expected Value and the Volatility of the Nominal Excess Return on Stocks," Journal of Finance, 48, 1779-1801.

Granger, C. W. J., And N. Hyung (2004): "Occasional Structural Breaks and Long Memory with an Application to the S\&P 500 Absolute Stock Returns," Journal of Empirical Finance, $11,399-421$.

Kim, T.-H., And H. White (2004): "On More Robust Estimation of Skewness and Kurtosis," Finance Research Letters, 1, 56-73.

Lamoureux, C. G., and W. D. Lastrapes (1990): "Persistence in Variance, Structural Change, and the GARCH Model," Journal of Business \& Economic Statistics, 8, 225-234. 
Luukkonen, R., P. Saikkonen, and T. Teräsvirta (1988): "Testing Linearity Against Smooth Transition Autoregressive Models," Biometrika, 75, 491-499.

McCracken, M. W. (2007): "Asymptotics for Out of Sample Tests of Granger Causality," Journal of Econometrics, 140, 719-752.

Mikosch, T., And C. StăRică (2004): "Nonstationarities in Financial Time Series, the LongRange Dependence, and the IGARCH Effects," Review of Economics and Statistics, 86, 378390.

Song, P. X., Y. Fan, and J. D. Kalbfleisch (2005): "Maximization by Parts in Likelihood Inference," Journal of the American Statistical Association, 100, 1145-1158.

StăRică, C., And C. W. J. Granger (2005): "Nonstationarities in Stock Returns," The Review of Economics and Statistics, 87, 503-522.

van Bellegem, S., and R. von Sachs (2004): "Forecasting Economic Time Series with Unconditional Time-Varying Variance," International Journal of Forecasting, 20, 611-627. 


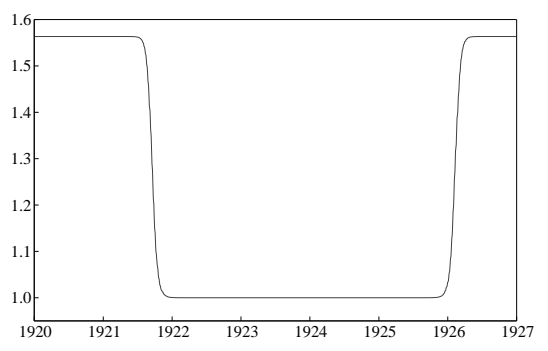

(a) Subperiod 1

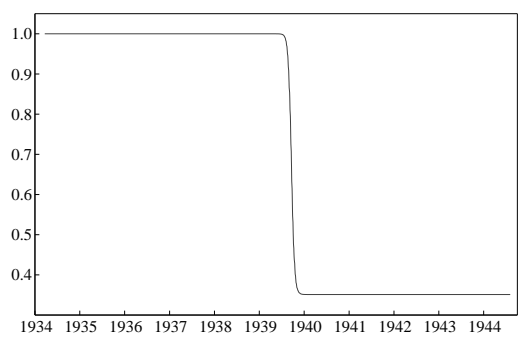

(c) Subperiod 3

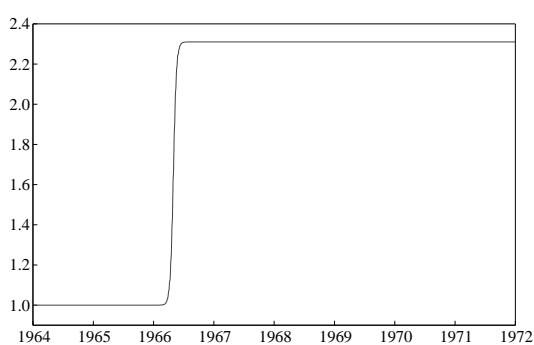

(e) Subperiod 6

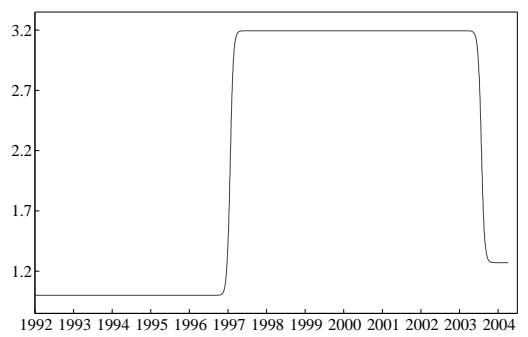

(g) Subperiod 9

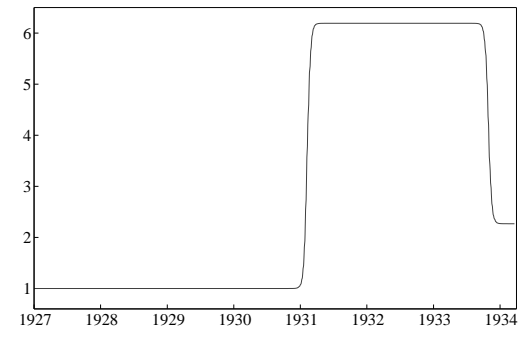

(b) Subperiod 2

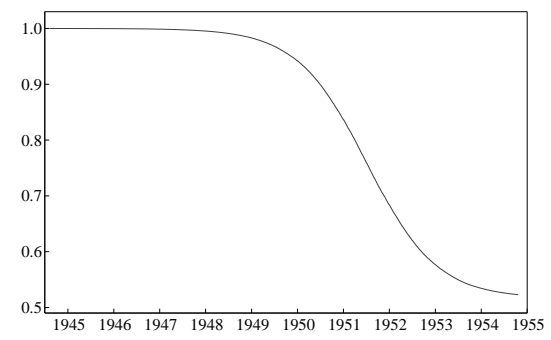

(d) Subperiod 4

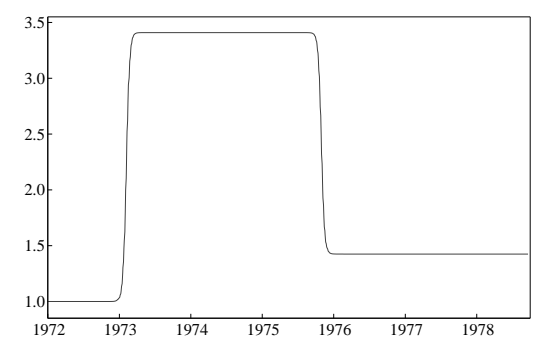

(f) Subperiod 7

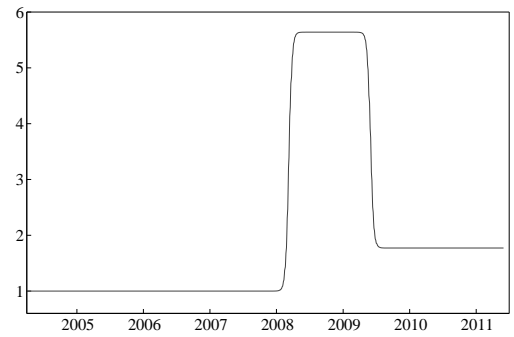

(h) Subperiod 10

Figure 6: Estimated $g_{t}$ functions for the eight subperiods. 


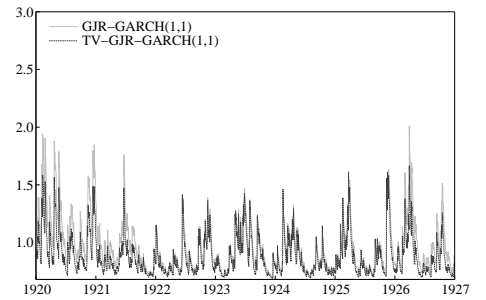

(a) Subperiod 1

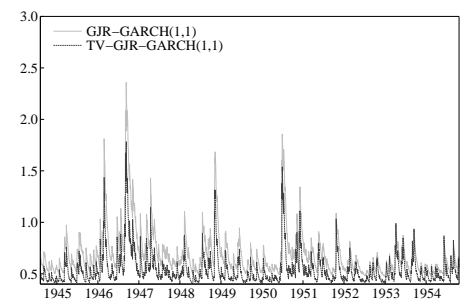

(d) Subperiod 4

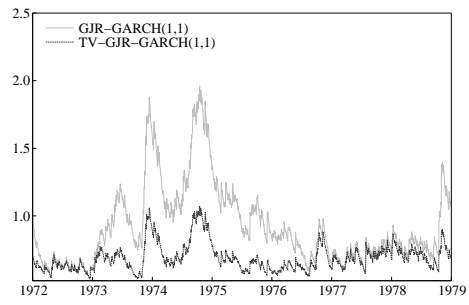

(g) Subperiod 7

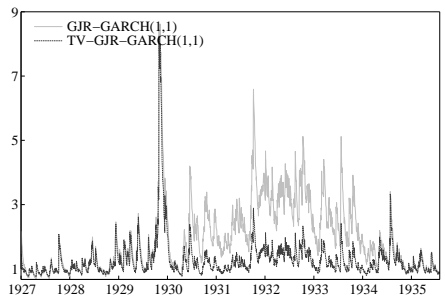

(b) Subperiod 2

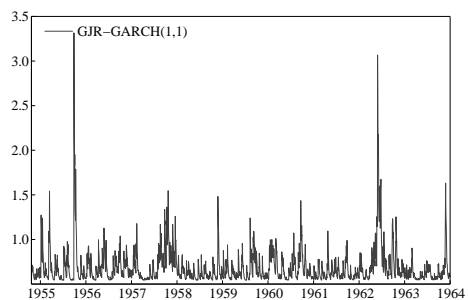

(e) Subperiod 5

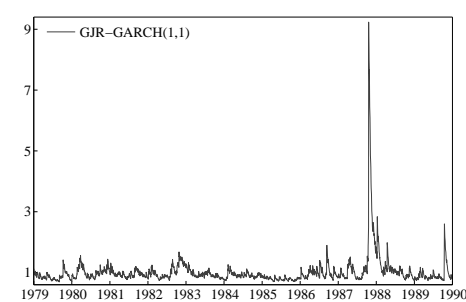

(h) Subperiod 8

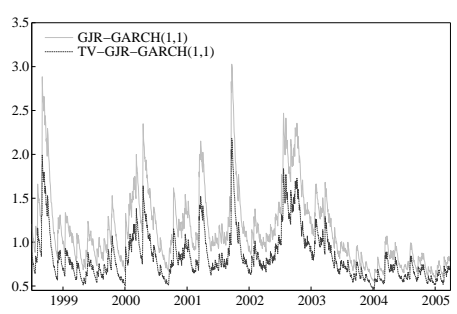

(j) Subperiod 10

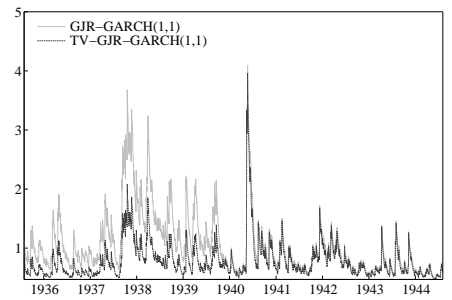

(c) Subperiod 3

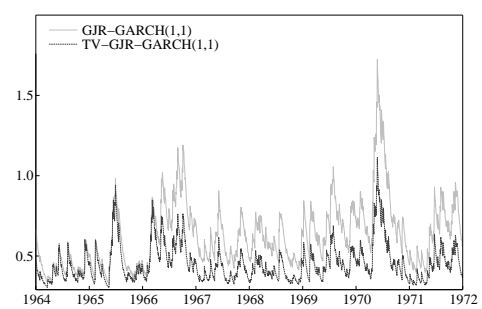

(f) Subperiod 6

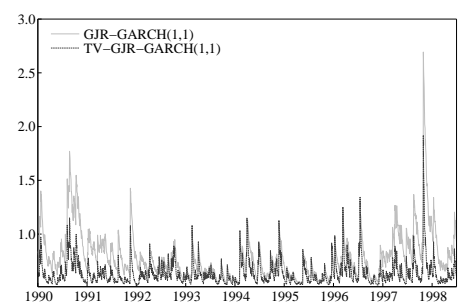

(i) Subperiod 9

Figure 7: Conditional standard deviations of the GJR-GARCH $(1,1)$ and the TV-GJR$\operatorname{GARCH}(1,1)$ model for the ten subperiods. 
Table 11: Summary statistics of the subperiod return series

\begin{tabular}{|c|c|c|c|c|c|c|c|c|}
\hline Subperiod & Min & $\overline{\mathrm{Max}}$ & Mean & S.D. & $\overline{\text { Skew }}$ & Ex.Kr. & Rob.Sk. & Rob.Kr. \\
\hline \multicolumn{9}{|c|}{ Subperiod 1: $T=1752$} \\
\hline$\overline{\varepsilon_{t}}$ & -4.524 & 5.365 & 0.021 & 1.001 & -0.446 & 1.979 & -0.023 & 0.124 \\
\hline$\varepsilon_{t} / \widehat{g}_{t}^{1 / 2}$ & -3.772 & 4.291 & 0.026 & 0.902 & -0.466 & 1.480 & -0.021 & 0.097 \\
\hline \multicolumn{9}{|c|}{ Subperiod $2: T=1799$} \\
\hline$\overline{\varepsilon_{t}}$ & -14.47 & 14.27 & -0.026 & 2.308 & 0.100 & 5.302 & -0.105 & 0.307 \\
\hline$\varepsilon_{t} / \widehat{g}_{t}^{1 / 2}$ & -14.47 & 11.64 & -0.007 & 1.505 & -0.918 & 12.65 & -0.013 & 0.195 \\
\hline \multicolumn{9}{|c|}{ Subperiod $3: T=2599$} \\
\hline$\overline{\varepsilon_{t}}$ & -7.469 & 9.090 & 0.015 & 1.158 & -0.495 & 6.204 & 0.011 & 0.325 \\
\hline$\varepsilon_{t} / \widehat{g}_{t}^{1 / 2}$ & -7.043 & 5.829 & 0.008 & 0.830 & -0.746 & 8.038 & 0.024 & 0.239 \\
\hline \multicolumn{9}{|c|}{ Subperiod $4: T=2346$} \\
\hline$\overline{\varepsilon_{t}}$ & -5.716 & 3.517 & 0.028 & 0.735 & -0.993 & 6.201 & 0.044 & 0.169 \\
\hline$\varepsilon_{t} / \widehat{g}_{t}^{1 / 2}$ & -3.945 & 2.428 & 0.021 & 0.540 & -0.934 & 5.189 & 0.037 & 0.124 \\
\hline \multicolumn{9}{|c|}{ Subperiod 5: $T=2517$} \\
\hline$\overline{\varepsilon_{t}}$ & -6.766 & 4.579 & 0.040 & 0.708 & -0.512 & 7.683 & -0.004 & 0.108 \\
\hline \multicolumn{9}{|c|}{ Subperiod $6: T=1991$} \\
\hline$\varepsilon_{t}$ & -3.193 & 4.952 & 0.008 & 0.664 & 0.298 & 3.258 & -0.040 & 0.096 \\
\hline$\varepsilon_{t} / \widehat{g}_{t}^{1 / 2}$ & -2.101 & 3.258 & 0.008 & 0.474 & 0.166 & 2.351 & -0.038 & 0.065 \\
\hline \multicolumn{9}{|c|}{ Subperiod $7: T=1696$} \\
\hline$\overline{\varepsilon_{t}}$ & -3.567 & 4.603 & -0.002 & 0.965 & 0.232 & 1.289 & 0.019 & $6 \times 10^{-5}$ \\
\hline$\varepsilon_{t} / \widehat{g}_{t}^{1 / 2}$ & -1.932 & 2.493 & 0.002 & 0.640 & 0.184 & 0.150 & 0.045 & -0.052 \\
\hline \multicolumn{9}{|c|}{ Subperiod $8: T=3357$} \\
\hline$\overline{\varepsilon_{t}}$ & -25.63 & 9.666 & 0.039 & 1.103 & -3.760 & 91.62 & -0.004 & 0.147 \\
\hline \multicolumn{9}{|c|}{ Subperiod $9: T=3130$} \\
\hline$\overline{\varepsilon_{t}}$ & -7.455 & 6.155 & 0.038 & 1.038 & -0.262 & 4.718 & 0.032 & 0.221 \\
\hline$\varepsilon_{t} / \widehat{g}_{t}^{1 / 2}$ & -4.171 & 3.443 & 0.033 & 0.683 & -0.249 & 2.442 & 0.041 & 0.132 \\
\hline \multicolumn{9}{|c|}{ Subperiod $10: T=1799$} \\
\hline$\overline{\varepsilon_{t}}$ & -8.201 & 10.51 & 0.010 & 1.253 & 0.012 & 11.34 & -0.024 & 0.460 \\
\hline$\varepsilon_{t} / \widehat{g}_{t}^{1 / 2}$ & -3.453 & 4.425 & 0.016 & 0.795 & -0.191 & 2.522 & -0.037 & 0.325 \\
\hline
\end{tabular}

Notes: The table contains summary statistics for each of the subperiod series. The sample periods are indicated in parentheses. The statistic 'S.D.' is the standard deviation, 'Skew' is the coefficient of skewness and the statistic 'Ex.Kr' is the value of the excess kurtosis. 'Rob.Sk.' denotes the robust measure for skewness and 'Rob.Kr.' denotes the robust centred coefficient for kurtosis. 'Rob.Sk.' is computed as $S K=\left(Q_{3}+Q_{1}-2 Q_{2}\right) /\left(Q_{3}-Q_{1}\right)$ where $Q_{i}$ is the $i$ th quartile of the returns and 'Rob.Kr.' is computed as $K R=\left(E_{7}-E_{5}+E_{3}-E_{1}\right) /\left(E_{6}-E_{2}\right)-1.23$ where $E_{i}$ is the $i$ th octile (see Kim and White (2004) for details). 
Table 12: Estimation results of the TV-GJR-GARCH(1,1) model: subperiods

\begin{tabular}{cccccccc}
\hline \hline Subperiod & $\widehat{\delta}_{1}$ & $\widehat{\gamma}_{1}$ & $\widehat{c}_{11}$ & $\widehat{c}_{12}$ & $\widehat{\delta}_{2}$ & $\widehat{\gamma}_{2}$ & $\widehat{c}_{21}$ \\
\hline Subperiod 1 & 0.5634 & 300 & 0.2463 & 0.8720 & - & - & - \\
& $(0.0866)$ & $(-)$ & $(0.0017)$ & $(0.0035)$ & & & \\
Subperiod 2 & 5.1922 & 300 & 0.5704 & - & -3.9244 & 300 & 0.9466 \\
& $(0.3353)$ & $(-)$ & $(0.0008)$ & & $(0.4721)$ & $(-)$ & $(0.0026)$ \\
Subperiod 3 & -0.6493 & 300 & 0.5301 & - & - & - & - \\
& $(0.0142)$ & $(-)$ & $(0.0008)$ & & & & \\
Subperiod 4 & -0.5242 & 11.325 & 0.7413 & - & - & - & \\
& $(0.0334)$ & $(4.7980)$ & $(0.0161)$ & & & & \\
Subperiod 6 & 1.3103 & 300 & 0.2957 & - & - & - & - \\
& $(0.0870)$ & $(-)$ & $(0.0009)$ & & & & \\
Subperiod 7 & 2.4090 & 300 & 0.1627 & - & -1.9841 & 300 & 0.5701 \\
& $(0.1833)$ & $(-)$ & $(0.0005)$ & & $(0.1979)$ & $(-)$ & $(0.0023)$ \\
Subperiod 9 & 2.1948 & 300 & 0.4125 & - & -1.9239 & 300 & 0.9440 \\
& $(0.1109)$ & $(-)$ & $(0.0011)$ & & $(0.1780)$ & $(-)$ & $(0.0025)$ \\
Subperiod 10 & 4.6399 & 300 & 0.5484 & - & -3.8683 & 300 & 0.7206 \\
& $(0.4526)$ & $(-)$ & $(0.0011)$ & & $(0.4663)$ & $(-)$ & $(0.0013)$ \\
\hline
\end{tabular}

Notes: The table contains the parameter estimates of the $g_{i t}$ component from the TV-GJR-GARCH $(1,1)$ model for each of the subperiods of the DJIA daily returns from January 2, 1920 until May 31, 2011. The estimated model has the form $g_{i t}=1+\sum_{l=1}^{r} \delta_{i l} G_{i l}\left(t / T ; \gamma_{i l}, \mathbf{c}_{i l}\right)$, where $G_{i l}\left(t / T ; \gamma_{i l}, \mathbf{c}_{i l}\right)$ is defined in (8) for all $i$. The numbers in parentheses are the standard errors.

Table 13: Estimation results of the TV-GJR-GARCH(1,1) model: subperiods

\begin{tabular}{|c|c|c|c|c|c|c|}
\hline Subperiod & 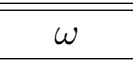 & 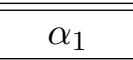 & $\overline{\kappa_{1}}$ & $\overline{\bar{\beta} \beta_{1}}$ & Log-Lik & 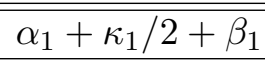 \\
\hline Subperiod 1 & $\begin{array}{l}0.0724 \\
(0.0294)\end{array}$ & - & $\begin{array}{l}0.1247 \\
(0.0356)\end{array}$ & $\begin{array}{l}0.8444 \\
(0.0513)\end{array}$ & -2246.1 & 0.907 \\
\hline Subperiod 2 & $\begin{array}{l}0.0876 \\
(0.0270)\end{array}$ & $\begin{array}{l}0.0301 \\
(0.0149)\end{array}$ & $\begin{array}{l}0.1686 \\
(0.0395)\end{array}$ & $\begin{array}{l}0.8374 \\
(0.0281)\end{array}$ & -2933.9 & 0.952 \\
\hline Subperiod 3 & $\begin{array}{l}0.0238 \\
(0.0108)\end{array}$ & $\begin{array}{l}0.0219 \\
(0.0118)\end{array}$ & $\begin{array}{l}0.1142 \\
(0.0398)\end{array}$ & $\begin{array}{l}0.8839 \\
(0.0377)\end{array}$ & -2912.1 & 0.963 \\
\hline Subperiod 4 & $\begin{array}{l}0.0179 \\
(0.0111)\end{array}$ & - & $\begin{array}{l}0.1253 \\
(0.0610)\end{array}$ & $\begin{array}{l}0.8729 \\
(0.0652)\end{array}$ & -1736.3 & 0.936 \\
\hline Subperiod 6 & $\begin{array}{l}0.0065 \\
(0.0020)\end{array}$ & - & $\begin{array}{l}0.1025 \\
(0.0172)\end{array}$ & $\begin{array}{l}0.9197 \\
(0.0157)\end{array}$ & -1197.6 & 0.971 \\
\hline Subperiod 7 & $\begin{array}{l}0.0086 \\
(0.0032)\end{array}$ & $\begin{array}{l}0.0243 \\
(0.0079)\end{array}$ & $\begin{array}{l}0.0279 \\
(0.0134)\end{array}$ & $\begin{array}{l}0.9411 \\
(0.0107)\end{array}$ & -1616.5 & 0.979 \\
\hline Subperiod 9 & $\begin{array}{l}0.0291 \\
(0.0074)\end{array}$ & - & $\begin{array}{l}0.1337 \\
(0.0282)\end{array}$ & $\begin{array}{l}0.8730 \\
(0.0254)\end{array}$ & -3105.8 & 0.940 \\
\hline Subperiod 10 & $\begin{array}{l}0.0181 \\
(0.0051)\end{array}$ & - & $\begin{array}{l}0.1478 \\
(0.0214)\end{array}$ & $\begin{array}{l}0.8944 \\
(0.0147)\end{array}$ & -1943.1 & 0.968 \\
\hline
\end{tabular}

Notes: The table contains the parameter estimates from the TV-GJR-GARCH(1,1) model for each of the subperiods of the DJIA daily returns from January 2, 1920 until May 31,2011 . The estimated model has the form of the equations (5)-(8). The numbers in parentheses are the standard errors. 
Table 14: Estimation results of the GJR-GARCH(1,1) model: subperiods

\begin{tabular}{|c|c|c|c|c|c|c|}
\hline Subperiod & $\bar{\omega}$ & $\alpha_{1}$ & 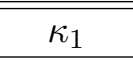 & $\overline{\beta_{1}}$ & Log-Lik & $\bar{c}_{1}+\kappa_{1} / 2+\beta_{1}$ \\
\hline Subperiod 1 & $\begin{array}{l}0.0560 \\
(0.0181)\end{array}$ & - & $\begin{array}{l}0.1145 \\
(0.0261)\end{array}$ & $\begin{array}{l}0.8811 \\
(0.0292)\end{array}$ & -2397.2 & 0.938 \\
\hline Subperiod 2 & $\begin{array}{l}0.0407 \\
(0.0137)\end{array}$ & $\begin{array}{l}0.0576 \\
(0.0127)\end{array}$ & $\begin{array}{l}0.1373 \\
(0.0316)\end{array}$ & $\begin{array}{l}0.8740 \\
(0.0159)\end{array}$ & -3621.4 & 1.000 \\
\hline Subperiod 3 & $\begin{array}{l}0.0186 \\
(0.0085)\end{array}$ & $\begin{array}{l}0.0281 \\
(0.0123)\end{array}$ & $\begin{array}{l}0.1036 \\
(0.0337)\end{array}$ & $\begin{array}{l}0.9072 \\
(0.0259)\end{array}$ & -3655.2 & 0.987 \\
\hline Subperiod 4 & $\begin{array}{l}0.0170 \\
(0.0115)\end{array}$ & - & $\begin{array}{l}0.0992 \\
(0.0487)\end{array}$ & $\begin{array}{l}0.9164 \\
(0.0435)\end{array}$ & -2421.9 & 0.966 \\
\hline Subperiod 5 & $\begin{array}{l}0.0810 \\
(0.0317)\end{array}$ & - & $\begin{array}{l}0.2353 \\
(0.0543)\end{array}$ & $\begin{array}{l}0.7175 \\
(0.0736)\end{array}$ & -2511.8 & 0.835 \\
\hline Subperiod 6 & $\begin{array}{l}0.0045 \\
(0.0015)\end{array}$ & - & $\begin{array}{l}0.0949 \\
(0.0140)\end{array}$ & $\begin{array}{l}0.9440 \\
(0.0089)\end{array}$ & -1801.4 & 0.991 \\
\hline Subperiod 7 & $\begin{array}{l}0.0043 \\
(0.0026)\end{array}$ & $\begin{array}{l}0.0232 \\
(0.0091)\end{array}$ & $\begin{array}{l}0.0403 \\
(0.0121)\end{array}$ & $\begin{array}{l}0.9526 \\
(0.0102)\end{array}$ & -2177.7 & 0.996 \\
\hline Subperiod 8 & $\begin{array}{l}0.0519 \\
(0.0328)\end{array}$ & $\begin{array}{l}0.0262 \\
(0.0106)\end{array}$ & $\begin{array}{l}0.0922 \\
(0.0652)\end{array}$ & $\begin{array}{l}0.8823 \\
(0.0574)\end{array}$ & -4648.7 & 0.955 \\
\hline Subperiod 9 & $\begin{array}{l}0.0142 \\
(0.0045)\end{array}$ & $\begin{array}{l}0.0145 \\
(0.0087)\end{array}$ & $\begin{array}{l}0.1092 \\
(0.0272)\end{array}$ & $\begin{array}{l}0.9199 \\
(0.0156)\end{array}$ & -4129.8 & 0.989 \\
\hline Subperiod 10 & $\begin{array}{l}0.0151 \\
(0.0049)\end{array}$ & - & $\begin{array}{l}0.1442 \\
(0.0235)\end{array}$ & $\begin{array}{l}0.9119 \\
(0.0140)\end{array}$ & -2367.3 & 0.984 \\
\hline
\end{tabular}

Notes: The table contains the parameter estimates from the GJR(1,1) model for each of the subperiods of the DJIA daily returns from January 2, 1920 until May 31, 2011. The estimated model has the form $h_{i t}=\omega_{i}+\alpha_{i 1} \varepsilon_{i t-1}^{2}+\beta_{i 1} h_{i t-1}+\kappa_{i 1} I_{i t-1}\left(\varepsilon_{i t-1}\right) \varepsilon_{i t-1}^{2}$, where $I_{i t}\left(\varepsilon_{i t}\right)=1$ if $\varepsilon_{i t}<0$ (and 0 otherwise) for all $i$. The numbers in parentheses are the Bollerslev-Wooldridge robust standard errors.

Table 15: GPH estimates of the long-memory parameter

\begin{tabular}{ccccccc}
\hline \hline & \multicolumn{2}{c}{$d_{G P H}\left(m=T^{0.4}\right)$} & \multicolumn{2}{c}{$d_{G P H}\left(m=T^{0.5}\right)$} & \multicolumn{2}{c}{$d_{G P H}\left(m=T^{0.6}\right)$} \\
\cline { 2 - 7 } Subperiods & $\varepsilon_{t}$ & $\varepsilon_{t} / \widehat{g}_{t}^{1 / 2}$ & $\varepsilon_{t}$ & $\varepsilon_{t} / \widehat{g}_{t}^{1 / 2}$ & $\varepsilon_{t}$ & $\varepsilon_{t} / \widehat{g}_{t}^{1 / 2}$ \\
\hline Subperiod 1 & 0.0545 & -0.3363 & 0.2600 & 0.0624 & 0.2009 & 0.0975 \\
& $(0.1987)$ & $(0.1924)$ & $(0.1204)$ & $(0.1363)$ & $(0.0744)$ & $(0.0821)$ \\
Subperiod 2 & 0.5077 & 0.2889 & 0.4264 & 0.4062 & 0.3220 & 0.4332 \\
& $(0.1838)$ & $(0.1402)$ & $(0.1195)$ & $(0.0890)$ & $(0.0662)$ & $(0.0651)$ \\
Subperiod 3 & 0.5333 & 0.3768 & 0.5282 & 0.3206 & 0.5199 & 0.4426 \\
& $(0.1271)$ & $(0.1375)$ & $(0.0911)$ & $(0.0871)$ & $(0.0593)$ & $(0.0588)$ \\
Subperiod 4 & 0.3233 & 0.2179 & 0.3934 & 0.3335 & 0.3417 & 0.3196 \\
& $(0.2113)$ & $(0.1987)$ & $(0.11134)$ & $(0.1080)$ & $(0.0670)$ & $(0.0669)$ \\
Subperiod 5 & -0.3827 & -0.3827 & 0.1667 & 0.1667 & 0.2356 & 0.2356 \\
& $(0.2110)$ & $(0.2110)$ & $(0.1362)$ & $(0.1362)$ & $(0.0745)$ & $(0.0745)$ \\
Subperiod 6 & 0.3945 & -0.0204 & 0.4545 & 0.1970 & 0.4245 & 0.2676 \\
& $(0.1558)$ & $(0.2681)$ & $(0.0913)$ & $(0.1303)$ & $(0.0645)$ & $(0.0801)$ \\
Subperiod 7 & 0.4273 & 0.2513 & 0.7126 & 0.5462 & 0.5407 & 0.4452 \\
& $(0.1404)$ & $(0.1045)$ & $(0.1022)$ & $(0.1157)$ & $(0.0770)$ & $(0.0763)$ \\
Subperiod 8 & 0.2233 & 0.2233 & 0.4350 & 0.4350 & 0.2978 & 0.2978 \\
& $(0.1052)$ & $(0.10515)$ & $(0.0715)$ & $(0.0715)$ & $(0.0497)$ & $(0.0497)$ \\
Subperiod 9 & 0.5211 & 0.1831 & 0.4464 & 0.2329 & 0.4137 & 0.2374 \\
Subperiod 10 & $0.1812)$ & $(0.2001)$ & $(0.1063)$ & $(0.1091)$ & $(0.0656)$ & $(0.0630)$ \\
& 0.6490 & 0.3541 & 0.8670 & 0.4839 & 0.7908 & 0.5307 \\
& $(0.0923)$ & $(0.1882)$ & $(0.1116)$ & $(0.1191)$ & $(0.0810)$ & $(0.0816)$ \\
\hline
\end{tabular}

Notes: The numbers in parentheses are the standard errors. The bandwidth $m$ equals $T^{\alpha}, \alpha \in\{0.4,0.5,0.6\}$ where $T$ is the number of observations. 
Table 16: In-sample and out-of sample periods for the subsamples

\begin{tabular}{lcccc}
\hline \hline & \multicolumn{2}{c}{ In-sample } & \multicolumn{2}{c}{ Out-of-sample } \\
\cline { 2 - 5 } Subsamples & Period & $T$ & Period & $T$ \\
\hline Subsample 1 & $02 / 01 / 1920-31 / 12 / 1926$ & 1752 & $03 / 01 / 1927-30 / 06 / 1927$ & 125 \\
Subsample 2 & $03 / 01 / 1927-21 / 03 / 1934$ & 1799 & $22 / 03 / 1934-21 / 09 / 1934$ & 128 \\
Subsample 3 & $22 / 03 / 1934-04 / 08 / 1944$ & 2599 & $07 / 08 / 1944-06 / 02 / 1945$ & 126 \\
Subsample 4 & $07 / 08 / 1944-31 / 12 / 1953$ & 2346 & $04 / 01 / 1954-30 / 06 / 1954$ & 125 \\
Subsample 6 & $02 / 01 / 1964-31 / 12 / 1971$ & 1991 & $03 / 01 / 1972-30 / 06 / 1972$ & 127 \\
Subsample 7 & $03 / 01 / 1972-20 / 09 / 1978$ & 1696 & $21 / 09 / 1978-20 / 03 / 1979$ & 125 \\
Subsample 9 & $02 / 01 / 1992-06 / 04 / 2004$ & 3130 & $07 / 04 / 2004-06 / 10 / 2004$ & 126 \\
Subsample 10 & $07 / 04 / 2004-31 / 05 / 2011$ & 1799 & $01 / 06 / 2011-30 / 11 / 2011$ & 128 \\
\hline
\end{tabular}




\section{Most Recent Working Paper}

NIPE WP Amado, Cristina e Timo Teräsvirta, "Modelling Changes in the Unconditional Variance of

02/2012 Long Stock Return Series", 2012

NIPE WP Martins, Rodrigo e Francisco José Veiga, " Turnout and the modeling of economic conditions:

01/2012 Evidence from Portuguese elections", 2012

NIPE WP Agnello, L e Ricardo M. Sousa, “Fiscal Consolidation and Income Inequality ”, 2011

$34 / 2011$

NIPE WP Maria Caporale, G e Ricardo M. Sousa, “Are Stock and Housing Returns Complements or

33/2011 Substitutes? Evidence from OECD Countries", 2011

NIPE WP Maria Caporale, G e Ricardo M. Sousa, "Consumption, Wealth, Stock and Housing Returns:

32/2011 Evidence from Emerging Markets ", 2011

NIPE WP Luca Agnello, Davide Furceri e Ricardo M. Sousa, "Fiscal Policy Discretion, Private Spending,

31/2011 and Crisis Episodes ? ", 2011

NIPE WP Agnello, L e Ricardo M. Sousa, "How do Banking Crises Impact on Income Inequality? ", 2011

30/2011

NIPE WP Alexandre, Fernando, Luís Aguiar-Conraria, Pedro Bação e Miguel Portela, “A Poupança em

29/2011 Portugal", 2011

NIPE WP Alexandre, Fernando e Carmen Mendes, "Growth, Consumption and Political Stability in

28/2011 China", 2011

NIPE WP Baleiras, Rui Nuno, "Collective Efficiency Strategies: A Regional Development Policy

27/2011 Contribution for Competitiveness Enhancement”, 2011

NIPE WP $\quad$ Brekke, Kurt R., Rosella Levaggi, Luigi Siciliani e Odd Rune Straume, "Patient Mobility,

26/2011 Health Care Quality and Welfare", 2011

NIPE WP Aguiar - Conraria, Luís, Pedro C. Magalhães e Maria Joana Soares "Cycles in Politics:

25/2011 Wavelet Analysis of Political Time-Series", 2011

NIPE WP Agnello,Luca, Vitor Castro e Ricardo M. Sousa "How Does Fiscal Policy React to Wealth

24/2011 Composition and Asset Prices? ”, 2011

NIPE WP Silva, Hélia, Linda Veiga e Miguel Portela "Strategic Interaction in Local Fiscal Policy:

23/2011 Evidence from Portuguese Municipalities", 2011

NIPE WP Sousa, Ricardo M., "Wealth, Labour Income, Stock Returns and Government Bond Yields, and

22/2011 Financial Stress in the Euro Area", 2011

NIPE WP Sousa, João e Ricardo M. Sousa, “Asset Returns Under Model Uncertainty: Evidence from the

$21 / 2011$ euro area, the U.K. and the U.S. ", 2011

NIPE WP Sila, U e Ricardo M. Sousa, "Do Windfall Gains Affect Labour Supply? Evidence from the

20/2011 European Household Panel ", 2011

NIPE WP Jawadi, F., Sushanta K. Mallick e Ricardo M. Sousa, "Fiscal Policy in the BRICs", 2011

$19 / 2011$

NIPE WP Jawadi, F., Sushanta K. Mallick e Ricardo M. Sousa, "Monetary Policy Rules in the BRICS:

18/2011 How Important is Nonlinearity?", 2011

NIPE WP Magalhães, Pedro C., Luís Aguiar-Conraria e Michael S. Lewis-Beck, "Forecasting Spanish

17/2011 Elections", 2011

NIPE WP Aguiar-Conraria, Luís e Maria Joana Soares, “The Continuous Wavelet Transform: A

16/2011 Primer", 2011

NIPE WP Amado, Cristina e Timo Teräsvirta, "Conditional Correlation Models of Autoregressive

15/2011 Conditional Heteroskedasticity with Nonstationary GARCH Equations", 2011

NIPE WP Siciliani, Luigi, Odd Rune Straume e Roberto Cellini, "Quality competition with motivated

14/2011 providers and sluggish demand", 2011

NIPE WP Castro, Vítor, "The Portuguese Stock Market Cycle: Chronology and Duration Dependence",

13/2011 2011

NIPE WP Mallick, Sushanta K. e Ricardo M. Sousa “The real effects of financial stress in the Euro zone”,

12/2011 2011

NIPE WP Castro, Vítor, "The Portuguese Business Cycle: Chronology and Duration ", 2011

$11 / 2011$ 